\title{
The March 11, 2011 Tōhoku M9.0 Earthquake-induced Tsunami and Coastal Inundation along the Japanese Coast: A Model Assessment
}

\author{
Changsheng Chen ${ }^{\mathrm{a}, \mathrm{c}, \mathrm{g}}$, Zhigang Lai ${ }^{\mathrm{b}}$, R. C. Beardsley ${ }^{\mathrm{c}}$, Jun Sasaki ${ }^{\mathrm{d}}$, Jian Lin ${ }^{\mathrm{e}}$, Huichan Lin ${ }^{\mathrm{a}}$, \\ Rubao $\mathrm{Ji}^{\mathrm{f}, \mathrm{g}}$ and Yunfang $\mathrm{Sun}^{\mathrm{a}}$ \\ ${ }^{\mathrm{a}}$ School for Marine Science and Technology \\ University of Massachusetts-Dartmouth \\ New Bedford, MA 02748, USA \\ ${ }^{\mathrm{b}} \mathrm{School}$ of Marine Sciences \\ Sun Yat-Sen University \\ Guangzhou 510275, China \\ ${ }^{c}$ Department of Physical Oceanography \\ Woods Hole Oceanographic Institution \\ Woods Hole, MA 02543, USA \\ ${ }^{\mathrm{d}}$ Department of Socio-Cultural Environmental Studies \\ Graduate School of Frontier Sciences \\ The University of Tokyo \\ Kashiwanoha, Kashiwa, Chiba 277-8563, Japan \\ ${ }^{\mathrm{e}}$ Department of Geology \& Geophysics \\ Woods Hole Oceanographic Institution \\ Woods Hole, MA 02543, USA
}

\author{
${ }^{\mathrm{f}}$ Biology Department \\ Woods Hole Oceanographic Institution \\ Woods Hole, MA 02543, USA
}

${ }^{\mathrm{g}}$ International Center for Marine Studies

Shanghai Ocean University

Shanghai 201306, China

Corresponding Author: Changsheng Chen

Email: c1chen@umassd.edu

Phone: 508-910-6388 


\begin{abstract}
A high-resolution nested global-Japan coastal FVCOM system was used to simulate the March 11, 2011 Tōhoku M9 earthquake-induced tsunami waves and coastal inundation along the northeastern coast of Honshu Island in the western Pacific Ocean. Experiments were made with initial fields provided by five seismic rupture models under realistic conditions with inclusion of the Kuroshio, tides and wind forcing. Results show that the model-computed intensities and distributions of tsunami waves and subsequent coastal inundation could be significantly influenced by initial conditions, even though all five cases were capable of reproducing key features of the tsunami waves. Modeled tsunami waves featured a low dispersive, weakly nonlinear long wave controlled by hydrostatic dynamics. Non-hydrostatic effects only became significant when tsunami waves reached the inner shelf and the amplitude of the leading tsunami wave grew within $\mathrm{O}(1)$ of the local water depth (10 $\mathrm{m}$ or shallower). In both hydrostatic and nonhydrostatic cases, significant mixing occurred when the ratio of wave amplitude to local water depth grew to about 0.25 or greater. Model-predicted run-up was in good agreement with 2-D $\mathrm{N}$ wave analytical solutions on the northern coast around South Iwate where inundation was small, but not in the central Sendai coastal region where inundation was large and 3-D wave dynamics became significant. The experiments suggest that once local bathymetry is accurately configured and the intensity and shape of the initial bottom movement can be predicted, this nested FVCOM system is capable of making accurate predictions of tsunami waves and coastal inundation.
\end{abstract}


2 March 11, 2011 was a tragic day for Japan and the world. The M9.0 and M7.9 earthquakes 3 occurred roughly $70 \mathrm{~km}$ east of the Pacific coast of Tōhoku, Japan (Hayes, 2011; Simons et al.,

4 2011) (Figure 1), which produced a major tsunami, rapid coastal inundation, and caused serious

5 damage in the coastal zone resulting in 15,883 people deaths, $\sim 6,146$ injured and $\sim 2654$ missing 6 (http://www.npa.go.jp/archive/keibi/biki/higaijokyo.pdf). The tsunami also caused major

7 infrastructure damage at the Fukushima Dai-ichi Nuclear Power Plant (FDNPP) with the 8 meltdown of three reactors and major release of radiation into the air and coastal waters around 9 the plant. The radionuclide leaking at FDNPP led to the evacuation of the population near the 10 plant and an intense concern in Japan and around the world about the coastal environment and its 11 potential long-term impacts on the Pacific Ocean. The US National Science Foundation (NSF) 12 quickly funded a number of RAPID grants to investigate different aspects of the earthquake, 13 tsunami, inundation, and nuclear disaster (EERI, 2012). An interdisciplinary team of U.S. and 14 Japanese scientists (geophysics, physical and biological oceanography, coastal engineering) was 15 formed to make a model assessment of the March 11 earthquake, tsunami formation and 16 evolution, coastal inundation, and initial spread of the Fukushima radionuclides into the Pacific 17 Ocean (Beardsley et al., 2012).

18 Several scientific and technical issues arose during an initial stage of our research. First, if 19 only the tsunami was concerned, one could follow a traditional approach to simulate the tsunami 20 using a two-dimensional (vertically-integrated) shallow water equation model by specifying the 21 initial sea level change due to the earthquake (e.g., Sasaki et al., 2011, 2012; Kim et al., 2011).

22 For the March 11 Tōhoku earthquake event, however, the inundation produced by the tsunami 23 damaged the FDNPP facility and led to a serious release of radionuclides into the coastal ocean. 
1 If one attempted to extend the tsunami simulation to track the spread of radionuclides thereafter,

2 the flow field would be required. A better approach would be to use a three-dimensional (3-D)

3 ocean model capable of resolving the multi-scale barotropic and baroclinic advective processes

4 in the FDNPP-inner shelf and regional ocean complex (Figure 1). This model should include

5 realistic forcing conditions, not only for the initial perturbation of sea level but also for tidal,

6 wind and buoyancy forcing to simulate the coastal and regional circulation and stratification.

7 After the initial simulation of the March 11 tsunami and coastal inundation, this model could

8 then be used to track the initial spread of radionuclides (esp. Cs-137; half-life $\sim 30$ years) from

9 the FDNPP into and across the shelf (Lai et al., 2013). To our knowledge, simulating tsunami

10 waves using a 3-D stratified ocean model has not been tried in the past.

11 Second, after the earthquake, several seismic rupture models were proposed to examine 12 inversely the geophysical dynamics for this earthquake (Toda et al., 2011). These models were

13 based on seismic, geodetic and tsunami observations. While several modeling efforts were also

14 made to simulate the tsunami waves under idealized initial conditions (e.g. Yoon et al., 2011;

15 Kim et al., 2011; Chan and Liu, 2012), to our knowledge, no assessment has been performed by

16 simulating the tsunami and subsequent coastal inundation using an ocean model with realistic

17 forcing conditions and initial seafloor changes constructued based on multi-sources of

18 measurements at monitoring sites by these seismic models. Such an assessment could provide us

19 with an alternative independent evaluation of these seismic models for their reality and accuracy

20 in presenting the observed features of the tsunami waves and coastal inundation.

21 Third, scaling analysis suggested that the initial tsunami waves produced by the March 11,

222011 Japan earthquake were low-dispersive, weakly nonlinear long waves since the ratios of

23 water depth to wavelength and of wave amplitude to water depth were much smaller than one 
1 (Chan and Liu, 2012). It is unclear if hydrostatic dynamics is sufficient to simulate the

2 propagation and runup of these tsunami waves, particularly over the shelf and near the coast

3 where the tsunami waves could become strongly nonlinear as the wave amplitude grows closer to

4 or larger than the local water depth. For a given high resolution grid, running a model with

5 hydrostatic and non-hydrostatic dynamics, respectively, could allow us to examine the relative

6 importance of non-hydrostatic dynamics in the tsunami wave simulation.

$7 \quad$ Fourth, many efforts have been made on examining the behavior of the tsunami wave runup

8 (e.g. Carrier and Greenspan, 1957; Keller and Keller, 1964; Synolakis et al., 2008; Madsen and

9 Schäffer, 2010; Chan and Liu, 2012). Carrier and Greenspan (1957) derived an analytical

10 solution for a nonlinear wave equation for nonbreaking long waves climbing over a linear slope

11 in an inviscid shallow water ocean. Keller and Keller (1964) considered shallow water waves

12 propagating over a more realistic linear two-slope beach, but their analytical solution was valid

13 only for linear theory. A solution that could be applied for both linear and nonlinear shallow

14 water waves was derived by Synolakis et al. (2008) and Madsen and Schäffer (2010). All of

15 these analytical studies, however, were conducted for idealized 2-D $(x-z$ where $x$ is the cross-

16 isobath direction and $\mathrm{z}$ is the vertical direction) canonical problem in which the wave propagated

17 from a constant depth region to the linear slope with no lateral (along-isobath) variation. The

18 central Tōhoku shelf north of the FDNPP is characterized by a concave coastline, and our model

19 simulations of the March 11 Japan tsunami waves exhibited 3-D features as the waves reached

20 the coast. A comparison of our 3-D model simulations with these analytic theories could provide

21 new insight into their applicability and limits.

22 In addition to scientific issues, intense public attentions have focused on the radionuclides

23 leaking from FDNPP. It is unclear how the tsunami was amplified when it entered the FDNPP 
1 facility area from the shelf and how it affected the resulting inundation. The FDNPP facility

2 damage image (Figure 1) implied that the tsunami seemed higher on the southern side than on

3 the northern side, and more serious on the back rather than on the front. Did the facility

4 breakwaters (designed for a peak wave elevation of $5.0 \mathrm{~m}$ ) act to influence the flooding around

5 the FDNPP? Since the horizontal resolution and bathymetry used in previous models were too

6 coarse to resolve the near-shore tsunami propagation towards the FDNPP, these questions were

7 not addressed until our studies.

8 To address these issues, we developed an integrated seismic-ocean-tracer model system to

9 examine the tsunami formation, inundation, and initial spreading of Cs-137. In this paper, we

10 present our key results on the initial tsunami generation, subsequent propagation, and coastal

11 inundation. A subsequent paper (Lai et al., 2013) has investigated in more detail the dynamics

12 controlling the initial pathways of Cs-137 from the FDNPP to the shelf break.

13 Our model system features a nested global-Japan coastal FVCOM system. Using high-

14 resolution bathymetry and elevation data obtained from the Japan Oceanographic Data Center

15 and Geospatial Information Authority of Japan, the local model domain was configured with a

16 horizontal resolution up to $5 \mathrm{~m}$ in regions of complex inner-shelf-land topography and around the

17 FDNPP. Under realistic oceanic conditions that include the Kuroshio, tides and wind forcing, we

18 first conducted experiments with the initial March 11 earthquake bottom movements provided by

19 five advanced seismic rupture models. The seismic models were then evaluated through

20 comparisons of model-simulated sea level with observations at coastal tide gauges and model-

21 predicted inundation areas with inundation maps constructed from field survey results. We next

22 determined the relative importance of non-hydrostatic dynamics on the tsunami wave runup and

23 compared our model results with the analytic runup model solutions. 


\section{The Integrated Model System and Experiment Design}

2 The ocean model used in this study is a global-regional-coastal nested FVCOM system

3 (hereafter referred to as the nested global-Japan coastal FVCOM system) (Figure 2). FVCOM is

4 a prognostic, unstructured-grid Finite-Volume Community Ocean Model developed originally by

5 Chen et al. (2003) and upgraded by team efforts (Chen et al., 2006a-b, 2013). FVCOM solves the

6 flux form of the governing equations in control volumes constructed with multi-triangular

7 meshes using a second-order accurate discrete flux scheme. This model uses an unstructured grid

8 in the horizontal and a terrain-following coordinate in the vertical. The unstructured triangular

9 grid provides a better fitting of irregular coastal geometries and flexibility in adjusting the grid

10 resolution to capture the key physical processes (Chen et al., 2007). The finite-volume approach

11 ensures the conservation of mass, heat, salt, and tracer concentrations in the sense of numerical

12 computation. The latest version of FVCOM (v3.1.6) used in this study is a fully coupled current-

13 wave-sediment-ice model with multiple options for domain nesting, flooding/drying processes,

14 and hydrostatic/non-hydrostatic solvers (Chen et al., 2013). The wet/dry treatment algorithm

15 used to simulate the coastal inundation is described in appendix A.

16 The global-Japan coastal nested FVCOM system includes two models: 1) Global-FVCOM

17 and 2) Japan coastal FVCOM (JC-FVCOM). These models are nested through the common

18 boundary cells. Global-FVCOM uses the spherical version of FVCOM to cover the entire global

19 ocean with inclusion of all major rivers (Figure 2, left panel). Its grid features a horizontal

20 resolution varying from $2 \mathrm{~km}$ along Japan's coast to $25 \mathrm{~km}$ in the interior. A hybrid terrain-

21 following (s- to sigma-) coordinate system is used in the vertical, with a total of 45 layers, 10 and

225 uniform layers near the surface and bottom, respectively, in regions deeper than $225 \mathrm{~m}$,

23 switching to the sigma-coordinate in continental shelf and coastal regions shallower than $225 \mathrm{~m}$. 
1 The thickness of the uniform layers is $5 \mathrm{~m}$, so the hybrid coordinate transition occurs at the

2 location where all layers have uniform thickness of $5 \mathrm{~m}$. This hybrid coordinate prevents

3 numerical errors in the simulation of surface mixed layer and bottom boundary layer dynamics in

4 the interior of the ocean without losing vertical resolution in the shallower coastal regions.

5 Global-FVCOM is driven by a) astronomical tidal forcing with eight constituents $\left(\mathrm{M}_{2}, \mathrm{~S}_{2}, \mathrm{~N}_{2}\right.$,

$6 \mathrm{~K}_{2}, \mathrm{~K}_{1}, \mathrm{P}_{1}, \mathrm{O}_{1}$, and $\mathrm{Q}_{1}$ ), b) surface wind stress, c) net heat flux at the surface plus shortwave

7 irradiance in the water column, d) surface air pressure gradients, e) precipitation (P) minus

8 evaporation (E), and f) river discharge. The external forcings were generated by two sources: 1)

9 global NCEP/NCAR reanalysis data at a 6-hour time interval and a 1.88-degree resolution, and

10 2) regional MM5/WRF reanalysis data at a 1-hour time interval and a 10-km resolution. We

11 merged these two datasets together and interpolated into an hourly time interval time series at

12 each grid node. The heat flux was adopted from version 2 of the CORE (Common Ocean

13 Reference Experiment) global air-sea flux dataset. The river discharges were collected from

14 different countries. For the rivers terminating on the US and Canada coasts, the discharge data

15 were downloaded directly from the US USGS website (http://waterdata.usgs.gov/nwis) and the

16 Canadian website (http://www.wsc.ec.gc.ca/applications /H2O/index-eng.cfm). For the regions

17 where no river discharge data were available, we used the climatological data that are used for

18 the Navy global ocean model.

19 Global-FVCOM has been validated through a 50-year spin-up simulation and a 35-year 20 (1978-2012) hindcast assimilation (http://202.121.64.88:8000/fvcomwms/). An example for the

21 accuracy of the tidal simulation in the western Pacific coastal regions was given in $\mathrm{Hu}$ et al.

22 (2012), which suggested that the Global-FVCOM provides the same accuracy as regional tidal 23 models used in that region. 
JC-FVCOM was configured with horizontal resolution varying from $5 \mathrm{~km}$ near the boundary

2 nesting with Global-FVCOM to 5-10 $\mathrm{m}$ in the nearshore coastal region (including the FDNPP)

3 and inland up to a distance of $15 \mathrm{~km}$ from the coast (Figure 2, right panels). JC-FVCOM had the

4 same hybrid vertical coordinate system with 45 layers and was forced with the same 5 meteorological forcing as Global-FVCOM.

6 For this study, the Global-FVCOM hindcast started on January 1, 2011 with initial conditions

7 provided from the hindcast results of 2010 and continued to July 31, 2011. The M9.0 Tōhoku

8 earthquake struck at 5:46 UTC March 11 with its epicenter near $38.30^{\circ} \mathrm{N}, 142.37^{\circ} \mathrm{E}$ (USGS,

9 2011), causing a large change in the bottom bathymetry on the Japan trench mega-thrust area

10 east of northern Honshu Island. Within $\sim 2$ minutes, the bottom elevation over a large area $(200$

11 x $500 \mathrm{~km}$ ) shifted significantly, with a maximum uplift of $\sim 7 \mathrm{~m}$ and depression of $\sim 3.5 \mathrm{~m}$. At

12 6:15 UTC, a major M7.9 aftershock struck near $35.92^{\circ} \mathrm{N}, 141.38^{\circ} \mathrm{E}$, causing an additional bottom

13 elevation change in a smaller area near the southern coast. JC-FVCOM started running at 0:00

14 UTC on March 11, 2011 with nested boundary conditions provided by the Global-FVCOM and

15 sea level changes predicted by five seismic rupture models for the combined M9.0 mainshock

16 and M7.9 aftershock at 5:46 UTC on that day.

17 The seafloor changes predicted by the five seismic rupture models, which were described in

18 detail in Toda et al. (2011), are shown in Figure 3. The five cases were named as case-a for Wei

19 and Sladen (2011) and Simons et al. (2011), using data from teleseismic $P$, $S H$, and long period

20 surface waves plus static GPS; case-b for Fujii et al. (2011), using data from DART

21 tsunamigrams and tide gauges; case-c for Shao et al. (2011), using data from similar sources as

22 Wei and Slanden's except no GPS; case-d for Pollitz et al. (2011), using static GPS data; and

23 case-e for Yagi and Fukahata (2011), using data from teleseismic body waves. The seismic 
1 moment was defined as $\mathrm{M}_{0}=\mu D S$, where $\mu$ was the shear modulus of the rocks, $D$ was the

2 average slip on the earthquake rupture plane with the fault surface area $S$, while the earthquake

3 moment magnitude $\mathrm{M}_{\mathrm{w}}=\log \mathrm{M}_{0} / 1.5-10.73$ (Stein and Wysession, 2003). The M9.0 mainshock

4 plus the M7.9 aftershock yielded seismic moments of 4.5, 3.6, 5.7, 3.6 and $4.5 \mathrm{E}^{29}$ dyne-cm for

5 cases a-e, respectively. The vertical deformation of the seafloor were calculated for the five

6 seismic models and used as the driving force to trigger the simulated tsunami waves. However,

7 the earthquake-induced local crustal deformation along Japan's coastal regions were not included

8 when comparing model predictions with observations.

9 The seafloor changes predicted by these five seismic models significantly differed in both

10 magnitude and spatial distributions (Figure 3). The model-predicted orientations of the major

11 axis of vertical deformation of the seafloor were similar, but case-b and case-c had a much larger

12 vertical deformation than the other three cases. Although case-b and case-c showed the

13 maximum vertical deformation value, case-c covered a larger area than case-b. Case-a showed

14 that there was significant seafloor change north of $40^{\circ} \mathrm{N}$, while other cases did not.

15 At 5:00 UTC, 46 minutes before the mainshock struck, the surface circulation off northern

16 Honshu Island featured a strong offshore Kuroshio Current on the south with a large cyclonic

17 recirculation centered near $36.5^{\circ} \mathrm{N}, 142.5^{\circ} \mathrm{E}$, a small cyclonic eddy centered near $38.3^{\circ} \mathrm{N}$,

$18143.5^{\circ} \mathrm{E}$ between the Kuroshio recirculation and Oyashio Current, and weaker currents over the

19 continental shelf and upper slope (Figure 4). The mainshock was centered in a weak current zone

20 between the two cyclonic eddies and occurred near low tide, at which time currents near the

21 coastal region were of order $0.1-0.5 \mathrm{~m} / \mathrm{s}$ and the prevailing winds were northeasterly with a

22 speed of roughly $5 \mathrm{~m} / \mathrm{s}$.

\section{Tsunami Simulations}


JC-FVCOM with initial conditions from the five seismic models was capable of reproducing

2 the tsunami and coastal inundation. As an example, here we use case-a to describe the general

3 features of the tsunami simulations. Figure 5 shows three snapshots of the distribution of the

4 tsunami waves at 05:51:53, 06:15:03 and 06:42:23 (hours: minutes: seconds) UTC, March 11.

5 The initial leading tsunami wave propagated towards the coast and reached the northern and

6 southern coasts in about 30 minutes. Large reflections occurred from the northern and southern

7 coasts, turning clockwise on the north and counterclockwise on the south, rejointing the tsunami

8 waves that propagated towards the Miyagi coast. The largest inundation occurred along the

9 Miyagi coast in Sendai Bay, due to both the relatively low and flat land features and the tsunami

10 wave energy accumulation from the reflected waves on both the coasts. The 06:42:23 snapshot

11 clearly showed that the reflected waves tended to push the water from both sides towards the

12 center of the Miyagi coast. The primary wave had an initial phase speed of about $200 \mathrm{~m} / \mathrm{s}$ and

13 slowed down as the wave propagated across the shelf and towards the coast (Figure 6). By the

14 time when the primary wave reached the coast, the phase speed was about $30 \mathrm{~m} / \mathrm{s}$ on the northern

15 coast, $40 \mathrm{~m} / \mathrm{s}$ on the southern side, and $60-70 \mathrm{~m} / \mathrm{s}$ in the middle of Miyagi.

16 The FDNPP is located at $37.42^{\circ} \mathrm{N}, 141.03^{\circ} \mathrm{E}$ on the southern area of Miyagi coast (Figure 1,

17 Figure 6). When the mainshock primary wave entered this facility, it was split into two branches

18 by the northern and southern breakwaters, and the maximum surface water current speed

19 exceeded $27 \mathrm{~m} / \mathrm{s}$ (Figure 7), which was two times larger than the maximum currents measured by

20 tsunami video images taken in Kesennuma Bay (Fritz et al., 2012). The breakwaters, designed to

21 protect the nuclear facility from a smaller tsunami, also functioned as a wave guide to increase

22 the water flux onto the northern and southern ends of the facility. The water first flowed onto the

23 southern land and then onto the northern land. The water then retreated back into the facility 
1 from land. While much of the water drained back to the ocean after the primary wave, a

2 significant amount of water remained in the inland areas around nuclear reactors \#1-\#4 on the

3 south and nuclear reactors \#5-\#6 on the north. During and after flooding, multiple vortices or

4 whirlpools appeared near and inside the power plant facility areas, with diameters of roughly 50-

$5200 \mathrm{~m}$. During flooding, cyclonic vortices occurred and both cyclonic and anticyclonic vortices

6 were found when the water rapidly retreated back to the ocean.

7 The larger flooding that occurred on the southern side was a result of the higher sea level on

8 the southern breakwater. We compared the time series of the sea level at site A on the north and

9 site B on the south of the facility (Figure 8 ). The model predicted a maximum water level of

$1016.02 \mathrm{~m}$ at site $\mathrm{B}$ and $13.59 \mathrm{~m}$ at site $\mathrm{A}$, a difference of $2.43 \mathrm{~m}$. The model-predicted inundation

11 processes into the FDNPP were consistent with a satellite image made after the mainshock,

12 which showed large damage in the inland areas of reactors \#4 and \#3 on the south and reactor \#1

13 close to the middle branch of the intrused water (Figure 1). The vortices or whirlpools were

14 evident in photos taken during this event as well as in other inundated coastal areas (Kim et al.,

15 2011, Lynett et al., 2012), which was believed to be due to the rip current-driven return water

16 from the land after wave breakimg.

17 We compared model-predicted tsunami water levels with measurements from eight tide 18 gauges from Kuji to Fukushima along the eastern Japan coast that experienced significant

19 tsunami damage (Figure 1). The Kuji gauge failed during inundation so that the maximum water

20 level there was unknown. At Sendai New Port, the measurements showed a peak of $6.65 \mathrm{~m}$.

21 Since the gauge was destroyed a few seconds later, it was unclear if the decrease in water level

22 after that peak was real or caused by instrument failure. The rapid ground geometric deformation

23 caused by the earthquake also caused some measurement errors in amplitude and phase. The 
1 uncertainty caused by these errors was not taken into account in the model-data comparisons

2 presented here.

3 The FVCOM-predicted water levels significantly differed in the five cases even through all

4 cases resolved the main water level peak caused by the mainshock primary wave and subsequent

5 oscillations (Appendix B). The initial condition specified based on case-c was constructed with

6 almost the same data sources as case-a but without GPS. The tsunami intensity, however, was

7 overestimated in case-c and underestimated in case-a, with a better overall results in case-c

8 (Figure 9). The model predictions for cases a-c captured the peak amplitude and timing better

9 than those for cases d-e (Table 1). At North Iwate, Central Iwate, and South Iwate in the northern

10 area, case-c predicted the water level closest to observations, but the timing was better in case-a

11 at North Iwate and in case-b at Central Iwate and South Iwate. At Central Miyagi, case-a showed

12 the best simulation for water level, and case-b predicted the best timing. At Sendai New Port, all

13 five cases caught the first largest tsunami peak, not only in amplitude but also in timing. Case-b

14 predicted the most accurate water level, and case-c showed the best timing. If one considered the

15 overall performance based on both water level and phase, case-a was better at this site. At

16 Fukushima, case-b and case-a were the best in amplitude and timing, respectively. These results

17 indicate that the tsunami wave simulation clearly depended on the spatial and temporal

18 distributions of the seafloor change predicted by seismic rupture models. Tsunami simulation

19 results based on an initial condition of idealized seafloor change should be interpreted with 20 caution.

\section{Inundation}

22 Configured with 5- to 10-m resolution of the coastal zone bathymetry and land elevation, JC-

23 FVCOM succeeded in reproducing the basic inundation process and flooded areas. The model- 
1 predicted inundation areas made with the five seismic initial conditions were in reasonable

2 agreement with field survey measurements made by Japanese national and local governments,

3 academic, and other groups (Mori et al., 2011) (Appendix B). For simplicity, we grouped the

4 survey areas into two regions: Region-I, where the most serious inundation occurred (Figure 10,

5 left panel), and Region-II, the coastal area north of Region-I. We computed the spatial extent of

6 the simulated flooding and compared these areas with those determined by both ground and

7 satellite-based measurements (Table 2). In Region-I, cases a-d showed better agreement with

8 measurement than case-e, with the closest agreement obtained in case-c. The model-

9 measurement difference was about $4-6 \mathrm{~km}^{2}$ for cases a-b and d, only about $1.9 \mathrm{~km}^{2}$ for case-c,

10 but about $12.5 \mathrm{~km}^{2}$ for case-d. These differences, for example, could be identified in Figure 10

11 for case-a. Region-II covered the more rugged area north of Central Miyagi, which included

12 several rivers. In this region, the inundation area was significantly overestimated by $1.7 \mathrm{~km}^{2}$

13 (about 38\%) in case-c and considerably underestimated by $1.6 \mathrm{~km}^{2}$ (about 36\%) in case-e. Case-a,

14 case-b, and case-d showed similar performance, with the closest agreement seen in case-a ( 15\%

15 underestimated). Cases a-d all were capable of reproducing the inundated spots, but the model-

16 predicted areas at these spots differed from measurements, particularly in the inland areas of the

17 rivers. This was partially due to the relatively lower accuracy of the coastal zone bathymetry and

18 land elevation in these areas and decreased grid resolution along this northern shore, while it was

19 clear that the extent of the predicted flooding was affected by the initial conditions specified by

20 the five seismic models. This result was consistent with the water level comparisons described in 21 section 3.

22 The model results for all five cases reproduced accurately the flooded areas in and around the

23 FDNPP (Table 2). Except in case-d, the inundated areas simulated in the other four cases were 
1 very close to the measurements, both in spatial distribution and boundary location. An example is

2 shown in Figure 10 (right panel) for the comparison of case-a and measurements. The major

3 inundation areas measured on the northern and southern regions of the facility were consistent

4 with the tsunami simulation results that a significant fraction of the primary tsunami wave water

5 transport was forced by the breakwaters to flow around the FDNPP and subsequently flood the

6 land on both sides and behind the facility.

\section{Contributions of Non-Hydrostatic Dynamics}

8 We have examined the importance of non-hydrostatic dynamics in the March 112013 Japan

9 tsunami wave simulation. No significant difference was observed for amplitude and propagation

10 speed of tsunami waves between hydrostatic and non-hydrostatic experiments until the waves

11 arrived in regions shallower than $\sim 10 \mathrm{~m}$ or less (Figure 6 and Figure 11). An example can be

12 seen in Figure 11 for the series of snapshots of surface elevation taken on a transect starting over

13 the shelf and ending at the FDNPP (shown as heavy black line in Figure 6). The surface

14 elevations simulated by hydrostatic and non-hydrostatic FVCOMs were almost identical over the

15 shelf until the waves reached site-C (shown in Figure 6) outside of the water passage between the

16 two breakwaters of FDNPP. The non-hydrostatic effect started as a vertical perturbation at the

17 crest of the leading tsunami wave at around 44 minutes after the earthquake, and then developed

18 into a high-frequency wave packet over a few minutes. The high-frequency wave train

19 overlapped over the hydrostatic surface elevation with a wider covering range extending to the

20 backside of the wave crest. This feature was believed to be due to reflection, since it was very

21 close to and inside the area bounded by the breakwaters. Non-hydrostatic processes resulted in a

22 relatively large high-frequency variation (up to a few meters) of surface elevation, but did not

23 change the general flooding tendency as that found in the hydrostatic case. The difference 
1 between the hydrostatic and non-hydrostatic tsunami waves can be clearly seen in snapshots of

2 the top-viewed distributions of surface elevation and near-surface current in Figure 12 and Figure

3 13. The leading tsunami wave propagated as a water "wall" towards FDNPP in the hydrostatic

4 case, while featuring a wave packet in the non-hydrostatic case. The distributions of the near-

5 surface currents remained similar in these two cases, but the currents in the non-hydrostatic cases

6 exhibited significant spatial variability. Due to the high-frequency fluctuation of surface

7 elevation, timing of the maximum flood onto FDNPP was delayed by a few seconds in the non-

8 hydrostatic case than in the hydrostatic case.

9 These model results indicated that non-hydrostatic dynamics became important in the region

10 where the water depth was $\sim 10 \mathrm{~m}$ or shallower. In this region, the amplitude of the tsunami

11 wave was about $5 \mathrm{~m}$ or higher. This was consistent with scaling analysis results, which

12 suggested that over the shelf where the ratio of wave amplitude to water depth was much smaller

13 than one the tsunami was a low-dispersive, weakly nonlinear long wave, and nonlinearity and

14 non-hydrostatic dynamics only became critical in the shallow region where this ratio was $\mathrm{O}(1)$.

\section{Impact of Tsunami on Vertical Mixing}

As explained in the introduction, one advantage of using the nested 3-D global-coastal ocean

18 model system is that it has already simulated the regional circulation and stratification, which is a

19 perquisite for tracking radionuclides from FDNPP. Since the tsunami was a solitary-type wave

20 with fast propagation speed (much greater than the ambient currents) and reached the coast in

21 roughly 0.5 to 1 hour, the regional circulation was unlikely to have a significant impact if only

22 the tsunami wave and coastal inundation were considered. To verify this point, we ran JC-

23 FVCOM by removing stratification and wind- and tide-driven circulation. The sea level

24 predicted by this barotropic case at tidal gauges was almost identical to the stratified case during 
1 the time before and when the peak of the tsunami wave arrived. A difference in the range of 0.1-

$21.0 \mathrm{~m}$ appeared in the subsequent oscillation period after the leading tsunami wave landed. This

3 implied that the background circulation and tides could have influences on the tsunami

4 oscillations caused by energy reflection after the leading tsunami wave arrived. We also

5 compared the model-predicted inundation areas for the cases with and without inclusion of

6 stratification. For example, for case-a forcing conditions, the barotropic case predicted a slightly

7 larger inundation area (up to 10\%) than the stratified case. Since this difference varied with

8 locations and was also related to initital conditions of the seafloor change in cases a-e, whether

9 or not the background regional circulation and stratification should be included in simulations of

10 the tsunami wave and inundation depends on what level of accuracy one would expect for the

11 tsunami wave simulation.

12 We did examine how the tsunami wave affected vertical stratification and mixing in our 3-D

13 simulations. In the continental shelf region, the tsunami behaved like a small-amplitude weakly-

14 nonlinear wave. When the leading wave passed, the local vertical temperature profile in the

15 upper $40 \mathrm{~m}$ showed a shift of $\sim 0.1-0.2^{\circ} \mathrm{C}$ (Figure 14). This shift had a maximum near the surface

16 and decreased with depth, which was believed due to Stoke's drift. This shift, however, did not

17 change the vertical stratification and thus mixing. The situation was different in the shallow

18 region where vertical mixing was considerably enhanced during the arrival and passage of the

19 leading wave. In this region (Figure 15), the ratio of wave's amplitude to local depth is $\mathrm{O}(0.25)$.

20 While the water column was lifted up, the mixing layer thickness (measured by a tempertature

21 range of $7.6-7.8^{\circ} \mathrm{C}$ ) significantly increased by $\sim 3-5$ meters in a few seconds. The fact that the

22 near-surface water was colder in the tsunami case implied that the wave intended to wrap the

23 cold water onto the shelf. In Figure 15, the colder water on the transect appeared at 39.8 minutes 
1 but not at a previous time, suggesting that this wraping process happened as a 3-D feature.

2 Similar vertical temperature profiles found in the hydrostatic and non-hydrostatic cases were

3 consistent with the results shown in section 5, where non-hydrostatic effects were negligible until

4 the ratio of wave amplitude to local depth increased to $\mathrm{O}(1)$.

5

6

7 10 derived a maximum runup law given as

12 where $R(t)$ is the maximum runup, $d$ is the local water depth, $\beta$ is the slope angle, and $H$ is the

13 initial solitary wave amplitude. Following Madsen and Schäffer (2010)'s analytical solution and

14 assuming the incident wave was composed of the combination of multi sech $(\cdot)^{2}$-profile waves,

15 Chan and Liu (2012) obtained the $N$-wave solution for the maximum runup $R(\tau)$ given as

\section{Comparisons with Analytical Solutions}

We compared the model-predicted runup of the tsunami waves with analytical solutions of solitary waves and so-called $N$-waves. Synolakis (1987) considered the runup of a sech $(\cdot)^{2}-$ profile solitary wave propagating from a constant depth region onto a linear slope region and

$$
R(t)=2.831 d(\cot \beta)^{\frac{1}{2}}\left(\frac{H}{d}\right)^{\frac{5}{4}}
$$

$$
R(\tau)=\sum_{n=1}^{N} R_{n}^{0} \operatorname{Li}\left(-\frac{3}{2},-e^{2 \theta_{n}}\right)-\frac{U^{2}}{2 g}
$$

17 where $N$ is the total number of sech $(\cdot)^{2}$-profile initial waves, $R_{n}^{0}=8 H_{n}\left(2 \pi \Omega_{n} t_{o}\right)^{\frac{1}{2}}$, Li ( ) is the

18 Jonquièrès function, $\theta_{n}=\Omega_{n}\left(\tau-t_{n}-2 t_{o}\right), U$ is the velocity given as

$19 U(\tau)=\sum_{n=1}^{N} \frac{2 \Omega_{n}}{s} R_{n}^{0} \operatorname{Li}\left(-\frac{5}{2},-e^{2 \theta_{n}}\right), \quad \tau=t-\frac{U(\tau)}{s g}, s$ is the beach slope, $\Omega_{n}$ is the $n$th wave

20 frequency, $t_{n}$ is the arbitrary phase shift, $t_{o}=\frac{h_{o}}{s \sqrt{g h_{o}}}, h_{o}$ is the local water depth, and $g$ is gravity.

21 For the same initial wave amplitude from the model, we compared the model-predicted 
1 maximum runup with analytical solutions (1) and (2) on the two selected sections shown in

2 Figure 6 (blue lines), and an example for the case-a simulation is shown in Figure 16.

3 On the north section, the bottom topography changed from $2000 \mathrm{~m}$ to a few meters over a

4 distance of $100 \mathrm{~km}$. This topography could be fitted well by a linear slope with a ratio of 1: 46.32

5 ( 0.02). Given an initial incident wave amplitude of $1.0 \mathrm{~m}$, the model-calculated runup agreed

6 very well with the $N$-wave solution. The runup predicted by the solitary wave solution (2)

7 matched well with both model-calculated and $\mathrm{N}$-wave solution-derived values in the region with

8 water depth $\geq 200 \mathrm{~m}$, but significantly underestimated the maximum runup (up to a value of 2.5

$9 \mathrm{~m}$ ) as the wave crossed the shallower region near the coast (For this comparison, the N-wave

10 runup was calculated with $N=1$, which was based on the fact that the solution with $N=1$

11 remained the same maximum wave height as the solution with $N>1$ (Chan and Liu, 2012)). The

12 north section was close to South Iwate. Chan and Liu (2012) compared solutions of solitary

13 waves and $N$-waves with runup observed at the TM1, TM2 and South Iwate stations (note: the

14 locations of TM1 and TM2 are almost on a cross-isobath transect from South Iwate, see Figure

15 1). By adjusting wave parameters, the $N$-wave solution reasonably matched the observations.

16 Due to poor matching of the time series of surface elevation observed at South Iwate by solitary

17 wave solution, Chan and Liu (2012) demonstrated that the March 112011 Japan tsunami was not

18 a solitary wave. Our comparison result on the north section was consistent with their finding, and

19 suggested that on this north section, for a given initial tsunami wave amplitude, $N$-wave theory

20 was capable of capturing the runup process like our 3-D primitive equation model.

21 On the south section, however, the model-calculated runup significantly differed from both

22 solitary wave and $N$-wave solutions. This section cut across the center of the concave Miyagi

23 shelf, on which the bottom depth changed from $1000 \mathrm{~m}$ to a few meter over a distance of $160 \mathrm{~km}$ 
1 (mean slope $\sim 0.0063$ ). The change of bottom depth with distance was not linear, with a slope of

$2 \sim 0.0097$ over the distance between $70 \mathrm{~km}$ and $160 \mathrm{~km}$ and $\sim 0.0021$ from $70 \mathrm{~km}$ to the coast.

3 These slopes were about 2.1 and 9.5 times smaller in comparison with the north section,

4 respectively. Given an initial incident wave amplitude of $1.8 \mathrm{~m}$ from the model-computed wave

5 height at $160 \mathrm{~km}$, the analytical solutions showed that a significant increase of runup when the

6 wave arrived in the shallow region with water depth $<100 \mathrm{~m}$. The maximum runup at the coast

7 was $10 \mathrm{~m}$ for the solitary wave solution but exceeded $20 \mathrm{~m}$ for the $N$-wave solution. With the

8 same initial wave amplitude, the model-predicted runup remained higher than the analytical

9 solutions from the initial location to the shelf about $30 \mathrm{~km}$ away from the coast. The maximum

10 difference was in a range of $2-3 \mathrm{~m}$. When the tsunami wave arrived near the coast, the wave

11 height dropped from $7 \mathrm{~m}$ to $5 \mathrm{~m}$ and then increased again to $7 \mathrm{~m}$ before the inundation occurred.

12 In this region, the model-predicted runup was significantly lower than the analytical solution.

13 The difference between the model and analytical solutions could be interpreted by two

14 reasons. First, the analytical solutions were derived using 2-D theory, but it was clear that the

15 tsunami wave in this concave-geometric shelf region was a 3-D feature with energetic wave

16 reflection from both northern and southern coasts (Figure 5). The higher wave height predicted

17 over the shelf by the model was believed to be due to the reflection energy, a process not

18 included in the 2-D solutions. Second, the analytical solutions were derived on an assumption of

19 a linear bottom slope. This assumption seemed to fit well on the north section but not on the

20 south section. Also, the reflection occurred after the tsunami arrived on the northern and southern

21 coast, which helped explain why the model matched the $N$-waves' solution well on the north

22 section but not on the south section. 
Our model showed that on the south section, runup dropped before the tsunami landed. This

2 feature was also related to wave reflection, which occurred over the shelf due to the concave 3 coastline. The effect of wave reflection around that period is clearly shown in Figure 17. At

463.33 minutes after the earthquake, the leading tsunami wave arrived in the shelf region about 25

$5 \mathrm{~km}$ away from the coast, where the wave height reached $\sim 7 \mathrm{~m}$ (Figure 16). Since the tsunami had

6 arrived on the northern part of the coast at this time, energy there was reflected and extended

7 southward just on the back of the leading wave (Figure 17). The effected area grew rapidly

8 southward in about 2.5 minutes, which tended to homogenize the wave height around the wave

9 crest (Figure 17). This was the cause for the drop of the runup before the leading tsunami wave

10 landed. When the leading tsunami wave was close to the coast, the runup increased again before

11 the inundation started.

\section{Discussion and Conclusions}

13

Our experiments have demonstrated that the nested global-Japan coastal FVCOM system

15 was capable of simulating the March 11, 2011 Tōhoku tsunami and coastal inundation. By

16 running the ocean model using the seafloor change predicted by five different seismic rupture

17 models as initial conditions, we provided an alternative oceanic evaluation of these seismic

18 models. Key findings from this "forward" simulation approach are summarized as follows. First,

19 for the given same ocean conditions, these seismic models were capable of reproducing the main

20 features of the tsunami and coastal inundation. However, the degree of agreement between the

21 FVCOM-predictions and observations varied significantly with the five different initial

22 conditions. Second, the fact that case-c with the highest seismic moment showed the best overall

23 simulation in both water level and spatial extent of coastal inundation implied that the moment of

24 these seismic models was a factor that could influence the ocean model simulation. However, 
1 this factor was certainly not the controlling parameter since case-e had the same moment as case-

2 a, but its performance was not as good as case-a. Also, case-b's moment was much lower than

3 case-c and case-a, but its performance was similar to case-a. Third, our experiments suggested

4 that including more data into the seismic rupture model did not always provide a better solution.

5 Case-c was developed with almost the same data sources as case-a but without GPS. The tsunami

6 intensity was overestimated in case-c and underestimated in case-a, but case-c provided a better

7 overall result. Finally, the seismic rupture models based on multiple monitoring data sources

8 have been widely used to study earthquake dynamics. Coupling seismic models with an ocean

9 model could provide an alternative tool to evaluate these seismic models and also enhance our

10 understanding of the possibility and reality for rapid prediction of a tsunami after an earthquake.

11 The good agreement of the model-simulated inundation areas with observations

12 demonstrated that with better resolution of coastal geometry for a given accurate local

13 bathymetry, an unstructured-grid nested-domain ocean model was capable of reproducing the

14 March 11, 2011 Japan tsunami and resulting coastal inundation. Significant differences in sea

15 level and inundation areas were found in the model-data comparisons, which suggested that it

16 was critical to capture the seismic moment of the earthquake and spatial distribution of the

17 seafloor change if one intended to use an ocean model to predict the tsunami and flooding. With

18 sufficient spatial resolution around the FDNNP facility, the model accurately predicted the

19 flooding observed at the facility and identified the key role of the breakwaters in the flooding 20 process.

21 The comparison of hydrostatic and non-hydrostatic experiment results indicated that the

22 March 112011 Japan tsunami was a weakly nonlinear long wave as it propagated from its origin

23 towards the coast. Non-hydrostatic effects became a critical factor in the shallow region where 
1 the amplitude of the leading tsunami wave grew to the same order of the local water depth. In

2 this case, the transition depth was about $10 \mathrm{~m}$ or shallower.

3 The initial tsunami wave developed 3-D features as it approached the Miyagi shelf caused by

4 wave reflection from the northern and southern coasts. The model-simulated runup matched well

5 with the $N$-wave analytical solution on the northern shelf where the bottom topography featured

6 a linear slope, but not in the concave Sendai Bay where the bottom topography was complex and

7 effects of wave reflections from northern and southern coastal regions were significant. Using 2-

8 D analytical solutions to interpret this tsunami event needs to be viewed with caution.

9 In the continental shelf region where the wave amplitude was much smaller than local water

10 depth, the arrival and passage of the initial tsunami wave caused little change in the vertical

11 stratification and essentially no mixing in both the hydrostatic and non-hydrostatic experiments.

12 This changed as the ratio of wave amplitude to local water depth grew to about 0.25 or greater,

13 thereafter significant mixing occurred. The effect of this change in stratification on the near-

14 shore currents and their role in the initial spread of radioactivity from the FDNPP was discussed

15 in Lai et al. (2013). 


\section{Appendix A: The FVCOM wet/dry point treatment Algorithms and validations}

2 One of the most difficult problems in the coastal inundation modeling is to provide an 3 accurate simulation of the water transport flooding onto and draining out of the land. In the last

4 three decades, two types of approaches have been developed to solve this issue: one is the 5 moving-boundary method and the other is the wet/dry point treatment method. In the first

6 method, the computational domain is bounded by an interface line between land and water where

7 total water depth and normal transport are equal to zero (Lynch and Gray, 1980). Because this

8 boundary moves over flooding and draining cycles, the model grid must be re-generated at every

9 time step. This method seems to work for idealized estuaries and coasts with simple geometries

10 (Sidén and Lynch, 1988; Austria and Aldama, 1990), but it is not easy for application to realistic

11 coastal regions with complex geometry including tidal creeks, islands, barriers, and inlets. In the

12 second method, the computational domain covers the maximum flooding area. Numerical grids

13 consist of wet and dry points with a boundary defined as an interface line between water and

14 land respectively. The wet and dry points are distinguished by the local total water depth of

$15 D=H(x, y)+\zeta(x, y, t)$ (where $H$ is the reference water depth and $\zeta$ is the surface elevation).

16 The wet point is a grid point with $D>0$, otherwise, $D=0$ at dry points. At dry points, velocities

17 are automatically specified as zero, but salinity retains the same value from the previous time

18 step. Since this method is relatively simple, it has been widely used to simulate the water

19 transport over inter-tidal areas in estuarine models (Leendertse, 1970 \& 1987; Flather and Heaps,

20 1975; Ip et al., 1998, Zheng et al., 2003, Chen et al., 2008).

21 The wet/dry point treatment technique works only for the case in which a finite-value

22 solution of the governing equations exists as $D$ approaches zero. In a $z$-coordinate system, to

23 ensure numerical stability of a 3-D model, the thickness of the layer closest to the surface must 
1 be greater than the amplitude of the tidal elevation (Davis et al., 1997). This makes it difficult to

2 apply this method for a shallow estuary in which the amplitude of the tidal elevation is the same

3 order of magnitude as the local water depth. Because irregular bathymetry is poorly resolved in a

4 z-coordinate model, it is not likely that the water transport can be accurately simulated over

5 realistic bathymetric inter-tidal zones during both flooding and draining periods. Examples of the

6 z-coordinate wet/dry methods can be seen in Casulli and Cheng (1991 \& 1992), Casulli and

7 Cattani (1994), and Hervouet and Janin (1994).

8 In a terrain-following coordinate system, the wet/dry point treatment is no longer valid as $D$

9 becomes zero. One simple way to avoid numerical singularity is to specify zero velocities at all

10 dry points. This approach, however, cannot ensure volume conservation in the numerical

11 computation due to discontinuous water removal from elements that turn to dry over one time

12 step. An alternative way is to add a viscous boundary layer $\left(D_{\min }\right)$ at the bottom and redefine

13 wet/dry points using a sum of $D$ and $D_{\min }$. The grid is treated as a wet point for D $>D_{\min }$,

14 otherwise it is a dry point. In terms of the nature of the vertical structure of turbulent mixing, a

15 viscous layer always exists below the log boundary layer near a solid wall (Wilcox, 2000).

16 However, to avoid adding additional water transport into a dynamic system, the viscous layer

17 should be sufficiently small to satisfy a motionless condition. In most of FVCOM applications,

18 we recommend a value of $D_{\min }=5 \mathrm{~cm}$ (Chen et al., 2006, 2013).

19 No matter which methods are used to simulate the flooding/draining process over the land 20 and intertidal wetlands, they must be validated with respect to mass conservation. In all of these

21 methods, the dry and wet points are determined using some empirical criteria, so that the

22 estimation of the water transport in the dry-wet transition zone depends on 1) the criterion used

23 to define the wet/dry points, 2) the time step used for numerical integration, 3) the horizontal and 
1 vertical resolutions of the model grids, 4) amplitudes of surface elevation, and 5) bathymetry. In

2 a terrain-following coordinate transformation model, it might be also related to the thickness of

3 the bottom viscous layer $\left(D_{m i n}\right)$.

4 A new wet/dry point treatment method was developed for use with FVCOM (Chen et al.,

5 2006b; Chen et al., 2008). This method has been validated in a series of tidal simulations using

6 an idealized semi-enclosed estuary with an inter-tidal zone. Relationships of the time step with

7 discrete grid resolution, amplitude of external forcing, the slope of the inter-tidal zone and

8 thickness of the bottom viscous layer are discussed and the criterion for the selection of the time

9 step has been derived (Chen et al., 2006b; 2013). The rule used in validation is mass

10 conservation, which, we believe, is a prerequisite condition for an objective evaluation of the

11 wet/dry point treatment technique in estuaries (and coastal regions where inundation occurs). A

12 detailed description of the criteria used to determine the wet and dry points can be found in the

13 FVCOM User Manuals (Chen et al., 2004, 2006b and 2013) and a brief summary is given here.

14 Defining that $D=H_{\mathrm{m}}+\zeta$, where $D=H_{\mathrm{m}}+D_{\min }$ in the water and $H_{\mathrm{m}}=-\left(h_{\mathrm{B}}+D_{\min }\right)$ on

15 the land (Figure A1), the wet or dry criterion for node points is given as

16

$$
\begin{cases}\text { wet } & \text { if } D=H_{\mathrm{m}}+\zeta>D_{\min } \\ \text { dry } & \text { if } D=H_{\mathrm{m}}+\zeta \leq D_{\text {min }}\end{cases}
$$

17 and for triangular cells is given as

$$
\left\{\begin{array}{l}
\text { wet } \quad \text { if } D=\min \left(H_{m, \hat{\imath}}, H_{m, \hat{\jmath}}, H_{m, \hat{k}}\right)+\max \left(\zeta_{\hat{\imath}}, \zeta_{\hat{\jmath}}, \zeta_{\widehat{k}}\right)>D_{\min } \\
\text { dry } \quad \text { if } D=\min \left(H_{m, \hat{\imath}}, H_{m, \hat{\jmath}}, H_{m, \hat{k}}\right)+\max \left(\zeta_{\hat{\imath}}, \zeta_{\hat{\jmath}}, \zeta_{\hat{k}}\right) \leq D_{\min }
\end{array}\right.
$$

19 where $D_{\min }$ is the thickness of the viscous layer specified at the bottom, $h_{B}$ is the bathymetric

20 height related to the edge of the main channel of a river (Figure A1) and $\hat{\imath}, \hat{\jmath}$ and $\hat{k}$ are the 21 integer numbers to identify the three node points of a triangular cell. 
When a triangular cell is treated as dry, the velocity at the centroid of this triangle is specified

2 to be zero and no flux is allowed on the three boundaries of this triangle. This triangular cell is 3 removed from the flux calculation in the TCE. For example, the integral form of the continuity 4 equation in FVCOM is written as

$$
\iint_{T C E} \frac{\partial \zeta}{\partial t} d x d y=-\iint_{T C E}\left[\frac{\partial(\bar{u} D)}{\partial x}+\frac{\partial(\bar{v} D)}{\partial y}\right] d x d y=-\oint_{l} \quad \bar{v}_{N} D d l
$$
where $\bar{u}$ and $\bar{v}$ are the $x$ and $y$ components of the vertically-averaged velocity. In a dry/wet point

7 system, only wet triangles are taken into account in the flux calculation in a TCE since the flux on boundaries of the dry triangle is zero (see Figure A2). This approach always ensures the

9 volume conservation in a TCE that contains the moving boundary between the dry and wet

10 triangles over an integration interval. The same approach is used to calculate the tracer flux

11 (temperature, salary and other scalar tracers) and momentum flux in a MCE.

12 One of the critical issues in applying the wet/dry point treatment technique in a split-mode 13 model is to ensure mass conservation in the individual TCE which is crossed by the moving 14 boundary. In a mode-split model, an adjustment must be made in every internal time step to 15 ensure the consistency in the vertically integrated water transport produced by external and 16 internal modes (Chen et al., 2004). In FVCOM, if the $\sigma$-coordinates are used, for example, the 17 vertical velocity at the $\sigma$ surface $(\quad$ ) is calculated by

$$
\omega_{i, k+1}=\omega_{i, k}+\frac{\Delta \sigma_{k}}{\Delta t_{I}}\left(\zeta_{i}^{n+1}-\zeta_{i}^{n}\right)+\frac{\Delta \sigma_{k}}{\Omega_{i}} \oint_{l} v_{N, k}^{n} D d l
$$

19 where $i, k$, and $n$ is indicators of the $i$ th node point, $k$ th $\sigma$ level and $n$th time step, respectively; $20 \Omega_{i}^{n}$ is the area of the $i$ th TCE at the $n$th time step. $N$ is an indicator of the velocity component 21 normal to the boundary of a TCE with a length of $l$. To conserve the volume on the $i$ th TCE, the 22 vertically integrated form of eq. (A. 4) must satisfy 


$$
\frac{\zeta_{i}^{n+1}-\zeta_{i}^{n}}{\Delta t_{I}}+\sum_{k=1}^{k b-1} \frac{\Delta \sigma_{k}}{\Omega_{i}^{n}} \oint_{l} v_{N, k}^{n} D d l=0
$$

2 where $k b$ is the total number of the $\sigma$ levels. Since $\zeta_{i}^{n+1}$ is calculated through the vertically

3 integrated continuity equation over $I_{\text {split }}$ external mode time steps (where $I_{s p l i t}=\frac{\Delta t_{I}}{\Delta t_{E}}$ ), Eq. (A.5)

4 is valid only if

$$
\Delta t_{I} \sum_{k=1}^{k b-1} \frac{\Delta \sigma_{k}}{\Omega_{i}^{n}} \oint_{l} v_{N, k}^{n} D d l=\Delta t_{E} \sum_{n=1}^{I_{s p l i t}} \frac{i}{\Omega_{i}^{\hat{n}}} \oint_{l} \bar{v}_{N}^{\hat{n}} D d l
$$

6 Because the numerical accuracy depends on the time step, the left and right sides of Eq. (A.6) is

7 not exactly equal to each other unless $I_{\text {split }}=1$. Therefore, to ensure the conservation of the

8 volume transport throughout the water column of the $i$ th TCE, the internal velocity in each $\sigma$ -

9 layer must be calibrated using the difference of an inequality of vertically integrated external and

10 internal water transport before is calculated. Since the vertically integrated transport features

11 the barotropic motion, the easiest calibration way is to adjust the internal velocity by distributing

12 the "error" uniformly throughout the water column. $\omega$, which is calculated with adjusted internal

13 velocities through Eq. (A.4), not only guarantees that the volume transport is conservative in the

14 whole water column but also in an individual TCE volume in each $\sigma$ layer. Because the water

15 temperature and salinity or other tracers are calculated in the same TCE volume as that used for

$16 \omega$, this transport adjustment also conserves the mass in an individual TEC volume in each $\sigma$

17 layer. When the wet/dry point treatment is calculated, however, because $\Omega_{i}^{\hat{n}}$ may change within

$18 I_{\text {split }}$ external time integrations due to the occurrence of dry triangles and $\zeta$ is treated as zero when

$19 D$ is less than $D_{\min }$, we have:

$$
\zeta_{i}^{n+1}-\zeta_{i}^{n} \neq \Delta t_{E} \sum_{n=1}^{I_{s p l i t}} \frac{1}{\Omega_{i}^{\hat{n}}} \oint_{l} \bar{v}_{N}^{\hat{n}} D d l
$$


In this case, the external and internal mode adjustment through Eq. (A.6) can not guarantee

2 that $\omega$ reaches zero at $\sigma=-1$ for the internal mode. To ensure the volume conservation, an 3 additional adjustment for $\zeta_{i}^{n+1}$ must be made in the TCE when is calculated by Eq.(A.5). The

4 additional sea level adjustment works in general, but fails in the case where $\zeta$ is very close to $5 D_{\min }$ (for example, $\Delta \zeta=\zeta-D_{\min }<10^{-1} \mathrm{~cm}$ ). When this happens, small errors in the 6 calculation of volume flux can rapidly accumulate through nonlinear feedback of tracer 7 advection terms and eventually destroy the nature of the mass conservation. The additional sea 8 level adjustment works in general, but fails in the case where $\zeta$ is very close to $D_{\min }$ (for 9 example, $\Delta \zeta=\zeta-D_{\min }<10^{-1} \mathrm{~cm}$ ). FVCOM always ensures the mass conservation in the 10 wet-dry transition zone if $I_{\text {split }}=1$. For computational efficiency, however, we want to find an 11 approach so that mass conservation is still guaranteed for the case in which $I_{\text {split }}>1$. In 12 additional to the criterion of general numerical instability, in a case with inclusion of the 13 flooding/drying process, the choice of $I_{\text {split }}$ is restricted by many other factors including the 14 surface elevation, bathymetry, and thickness of the bottom viscous layer and horizontal/vertical 15 resolutions. A discussion on the relationship of $I_{\text {split }}$ to these factors was given in detail in the 16 FVCOM User Manual with the update in Chen et al., (2013).

17 The wet/dry point treatment method of FVCOM was validated by an application to simulate 18 the tide-induced flooding/drying process in the estuarine-tidal creek-salt marsh complex of the 19 Okatee/Colleton River Estuary, South Carolina (SC) (Chen et al., 2008a,b, and unpublished 20 manuscripts). Hypsometric measurements were made using remote-sensing by Drs. Andrade and 21 Blanton at Skidaway Institute of Oceanography the upstream area of the Okatee River during the

22 flood period on November 9, 2001, during which the extent of the flooded area was accurately 23 mapped with a time interval of about one hour. The model-data comparisons showed that 
1 FVCOM was capable of reproducing tidal and residual currents in the river and the time

2 evolution of the flushing area onto salt marshes. This method succeeded in stimulating the

3 flooding/draining process in the Satilla River estuary, Georgia (Chen et al., 2008).

4

5

6

7

8

9

10

11

12

13

14

15

16

17

18

19

20

21

22

23 
Appendix B: Model-data comparison for water elevations and inundation areas for five

2 seismic model-predicted initial conditions.

3 The model-predicted tsunami water levels for cases-b, $d$ and e are shown and compared with

4 observations at available tidal gauges in Figure B1. Combined with cases-a and c shown in

5 Figure 9 in the text, it was clear that the model-predicted water level depended significantly on

6 the initial condition of the sea level predicted by seismic models. The difference varied in space

7 at different tidal gauges. At North Iwate, Central Iwate, and South Iwate in the northern area,

8 case-c predicted the smallest water level differences with observations, but the timing was better

9 in case-a at North Iwate and in case-b at Central Iwate and South Iwate. At Central Miyagi, case-

10 a showed the best simulation for water level, and case-b predicted the best timing. At Sendai

11 New Port, all five cases caught the first largest tsunami peak, not only in amplitude but also in

12 timing. Case-b predicted the most accurate water level, and case-c showed the best timing. If one

13 considered the overall performance based on both water level and phase, case-a was better at this

14 site. At Fukushima, case-b and case-a were the best in amplitude and timing, respectively.

15 The model-predicted inundation areas made for the five seismic initial conditions are shown

16 and compared with observations in Figure B2 (region-I), Figure B3 (region-II) and Figure B4

17 (FDNNP). Although the model-predicted inundation areas for these five cases were in

18 reasonable agreement with observations, it was clear that a significant error occurred in the more

19 rugged area north of Central Miyagi, which included several rivers. In this region, cases a-d all

20 were capable of reproducing the inundated spots, but the model-predicted areas at these sports

21 differed from measurements, particularly in the inland areas of the rivers. This was partially due

22 to the relatively lower accuracy of the coastal zone bathymetry and land elevation in these areas

23 and decreased grid resolution along this northern shore. The model results for all five cases were 
1 described in detail in the text based on Table 2. Figure B4 provides a view of the model-

2 predicted flooded areas in and around FDNPP for cases b-e.

3

4

5

6

7

8

9

10

11

12

13

14

15

16

17

18

19

20

21

22

23 
2 This project was supported by US NSF RAPID grants \#1141697 and \#1141785 and the JST

3 J-RAPID Program. The development of Global-FVCOM was supported by NSF grants 4 ARC0712903, ARC0732084, and ARC0804029. We would like to thank J. Qi at the Marine

5 Ecosystem Dynamics Laboratory for the development of multi-domain nesting modules in

6 FVCOM, and P. Xue, G. Gao, Q. Xu and Y. Zhang for their assistances in converting the results

7 into animations. C. Chen, R. Ji and H. Lin's contribution is also supported by the International

8 Center for Marine Studies at Shanghai Ocean University through "Shanghai Universities First9 class Disciplines Project”.

10

11

12

13

14

15

16

17

18

19

20 


\section{References}

Austria, P. M., Aldama, A. A., 1990. Adaptive mesh scheme for free surface flows with moving boundaries. In G. Gambolati, A. Rinaldo, C. A. Brebbiam, W. G. Fray, and G. F. Pinder (eds.), Computational methods in Surface Hydrology, Springer-Verlag, New York, p. 456-460.

Beardsley, R. C., Chen, C., Lai, Z., Sasaki, J. Lin, H., Lin, J., Ji, R., 2012. A US-Japan collaborative research on assessment of the March 112011 Earthquake, Tsunami Inundation and Initial Spread of Fukushima Dai-ichi Radionuclides into the Pacific Ocean. The 2012 Ocean Science Meeting, Salt Lake City. Abstract and poster.

Carrier, G., Greenspan, H. P., 1958. Water waves of finite amplitude on a sloping beach, Journal of Fluid Mechanics, 4, 97-109.

Casulli, V., Cheng, R. T., 1991. A semi-implicit finite-difference model for three-dimensional tidal circulation, p. 620-631. In M. Spaulding et al. (eds.), Proceeding of 2nd International Conference on Estuarine and Coastal Modeling, ASCE, Tampa, Florida.

Casulli, V., Cheng, R. T., 1992. Semi-implicit finite-difference methods for three-dimensional shallow-water flow. International Journal for Numerical Methods in Fluids, 15: 629-648.

Casulli, V., Cattani, E., 1994. Stability, accuracy and efficiency of a semi-implicit method for three-dimensional shallow water flow. Computers and Mathematics with Application, 27: 99-112.

Chan, I. C., Liu, P. L. F., 2012. On the runup of long waves on a plane beach. Journal of Geophysical. Research., 117, C08006, doi:10.1029/2012JC007994.

Chen, C., Liu, H., Beardsley, R. C., 2003. An unstructured grid, finite-volume, three dimensional, primitive equations ocean model: Application to coastal ocean and 
estuaries. Journal of Atmospheric and Ocean Technology, 20 (1), 159-186.

2 Chen, C, Cowles, G., Beardsley, R. C., 2004. An unstructured grid, finite-volume coastal ocean model: FVCOM User Manual, Second Edition. SMAST/UMASSD Technical Report-040601, pp 183.

Chen, C, Beardsley, R. C., Cowles, G., 2006a. An unstructured grid, finite-volume coastal ocean model (FVCOM) system. Special Issue entitled "Advances in Computational Oceanography”, Oceanography, 19(1), 78-89.

Chen, C, Cowles, G., Beardsley, R. C., 2006b. An unstructured grid, finite-volume coastal ocean model: FVCOM User Manual, Second Edition, SMAST/UMASSD Technical Report-060602, pp 315.

Chen, C., Huang, H., Beardsley, R. C., Liu, H., Xu, Q., Cowles, G., 2007. A finite-volume numerical approach for coastal ocean circulation studies: comparisons with finite difference models. Journal of Geophysical Research, 112, C03018, doi:10.1029/2006JC003485.

Chen, C, Qi, J., Li, C., Beardsley, R. C., Lin, H., Walker, R., Gates, K., 2008. Complexity of the flooding/drying process in an estuarine tidal-creek salt-marsh system: an application of FVCOM. Journal of Geophysical Research, 113, C07052doi: 10.1029/2007jc004328.

Chen, C., Qi, J, Liu, H., Beardsley, R. C., Lin, H., Cowles, G., 2008. A wet/dry point treatment method of FVCOM, part-I: stability experiments. Unpublished manuscript.

Chen, C., Huang, H., Lin, H., Blanton, J., Li, C., Andrade, F., 2008. A Wet/Dry Point Treatment Method of FVCOM, Part II: Application to the Okatee/Colleton River in South Carolina. Unpublished manuscript.

Chen, C., Beardsley, R. C., Cowles, G., Qi, J., Lai, Z., Gao, G., Stuebe, D., Liu, H., Xu, Q., Xue, 
P., Ge, J., Ji, R., Hu, S., Tian, R., Huang, H., Wu, L., Lin, H., Sun, Y., Zhao, L., 2013. An unstructured-grid, finite-volume community ocean model FVCOM user manual (3rd edition). SMAST/UMASSD Technical Report-13-0701, University of MassachusettsDartmouth, pp 404.

Davies, A. M., Jones, J. E., J. Xing, J., 1997. Review of recent developments in tidal hydrodynamic modeling, I: Spectral models. Journal of Hydraulic Engineering, ASCE, 123: 278-292.

EERI, 2012. The 2010 Canterbury and 2011 Christchurch New Zealand Earthquakes and the 2011 Tohoku Japan Earthquake: Emerging Research Needs and Opportunities. Workshop Report (available at http://www.eeri.org/japan - new - zealand - nsf-rapid - workshop/).

Flather, R. A., N. S. Heaps, N. S., 1975. Tidal computations for Morecambe Bay. Geophys. J. Roy. Astr. Soc., 42:489-517.

Fritz, H. M., Phillips, D. A., Okayasu, A., Shimozono, H. Liu, H., Mohammed, F., Skanavis, V., Synolakis, C. E., Takahashi, T., 2012. The 2011 Japan tsunami current velocity measurements from survivor videos at Kesennuma Bay using LiDAR. Geophysical. Research Letter, 39, L00G23, doi:10.1029/2011GL050686.

Fujii, Y., Satake, K., Sakai, S., Shinohara, M., Kanazawa, T., 2011. Tsunami source of the 2011 off the Pacific coast of Tohoku earthquake. Earth Planets Space, 63, 815-820, doi:10.5047/eps.2011.06.010.

Hayes, G. P., 2011. Rapid source characterization of the 2011 Mw 9.0 off the Pacific coast of Tohoku Earthquake. Earth Planets Space, 63(7), 529-534, doi:10.5047/eps.2011.05.012. 
1 Hervouet, J. M, Janin, J. M., 1994. Finite-element algorithms for modeling flood propagation, p. 102-113. In P. Molinaro and L. Natale (eds.), Modeling of Flood Propagation Over Initially Dry Areas, ASCE, New York.

Hu, S., Chen, C., Gao, G., Lai, Z., Ge, J., Lin, H., J. Qi, 2012. Preliminary analysis on the simulation of the East China Sea of the Global-FVCOM model. Journal of Shanghai Ocean University, 21(4), 621-629.

Ip, J. T. C., Lynch, D. R., Friedrichs, C. T., 1998. Simulation of estuarine flooding and dewatering with application to Great Bay, New Hampshire. Estuarine, Coastal and Shelf Science, 47:119-141.

Keller, J. B., Keller, H. B., 1964. Water wave run-up on a beach, PNR Research Rep. NR3828(00), Dep. of the Navy, Washington, D. C.

Kim, K. O., Choi, B. H., Min, B., 2011. Three dimensional simulation of 2011 East Japan-off Pacific coastal earthquake tsunami induced vorticity in the Oarai port. The Pacific Ocean Tsunami (in Korean Language), Korean Society of Coastal and Ocean Engineers, Printed by Hanrimwon Co. Ltd, 58-65pp.

Lai, Z., Chen, C., Beardsley, R. C., Lin, H., Ji, R., Sasaki, J., Lin, J., 2013. Initial spread of ${ }^{137} \mathrm{Cs}$ from the Fukushima Dai-ichi Nuclear Power Plant over the Japan continental shelf: a study using a high-resolution, global-coastal nested ocean model. Biogeosciences, 10, 5439-5449, doi:10.5194/bg-10-5439-2013.

Leendertse, J. J. 1970. A water-quality simulation model for well-mixed estuaries and coastal seas: principles of computation, Rand Corporation Report RM-6230-RC, Vol. I.

Leendertse, J. J. 1987. Aspects of SIMSYS2D, a system for two-dimensional flow computation. Rand Corporation Report R-3572-USGS. 
1 Lynch, D. R., Gray, W. G., 1980. Finite element simulation of flow in deforming regions.

2 Journal of Computational Physics, 36: 135-153

3 Lynett, P., Borrero, J. C., Weiss, R., Son, S., Greer, D., Renteria, W., 2012. Observations and

4 modeling tsunami-induced currents in ports and harbors. Earth and Planetary

$5 \quad$ Science Letter, 327-328, 68-74.

6 Madsen, P. A., Schäffer, H. A., 2010. Analytical solutions for tsunami runup on a plane beach:

7 Single waves, N-waves and transient waves. Journal of Fluid Mechanics., 645, 27-57.

8 Mori, N., Takahashi, T., Yasuda, T., Yanagisawa, H., 2011. Survey of 2011 Tohoku earthquake

9 tsunami inundation and run-up. Geophysical Research Letter, 38, L00G14, doi:

$10 \quad$ 10.1029/2011GL049210.

11 Pollitz, F., Bürgmann, R., Banerjee, P., 2011. Geodetic slip model of the 2011 M9.0 Tohoku

12 earthquake. Geophysical Research Letter, 38, L00G08, doi:10.1029/2011GL048632.

13 Sasaki, J., Ito, K., Kazunori, I., Suzuki, T., Wiyono, R. U. A., Oda, Y., Takayama, Y., Yokota,

14 K., Furata, A., Takagi, H., 2012. Behavior of the 2011 Tohoku earthquake tsunami and

15 resultant damage in Tokyo Bay. Coastal Engineering Journal, 54 (1), 1250012 (1-16),

16 doi: $10.1142 /$ So57856341250012X.

17 Sasaki J., Komatsu, T., Matsumaru, R., Wiyono, R. U. A., 2011. Unstructured model 18 investigation of 2004 Indian Ocean tsunami inundation in Banda Aceh, Indonesia. 19 Journal of Coastal Research, SI64, 941-945. ICE2011 (Proceedings), ISSN0749-0208.

20 Shao, G., Li, X., Ji, C., Maeda, T., 2011. Focal mechanism and slip history of the $2011 \mathrm{M}_{\mathrm{w}} 9.1$

21 off the Pacific coast of Tohoku earthquake, constrained with teleseismic body and surface

22 waves. Earth Planets Space, 63, 559-564, doi:10.5047/eps.2011.06.028. 
1 Sidén, G. L. D., Lynch, D. R., 1988. Wave equation hydrodynamics on deforming elements.

2 International Journal of Numerical Method in Fluids, 8: 1071-1093.

3 Simons, M., Minson, S. E., Sladen, A., Ortega, F., Jiang, J., Owen, S. E., Meng, L., Ampuero, J-

4 P., Wei, S., Chu, R., Helmberger, D. V., Kanamori, H., Hetland, E., Moore, A. W.,

5 Webb, F. H., 2011. The 2011 magnitude 9.0 Tohoku-Oki earthquake: Mosaicking the

6 megathrust from seconds to centuries. Science, 332, 1421-1425, $7 \quad$ doi:10.1126/science. 1206731.

8 Stein, S., Wysession, M., 2003. An Introduction to Seismology, Earthquakes, and Earth

9 Structure, Blackwell Publishing, Oxford, UK, 498 pp., ISBN 0865420785.

10 Synolakis, C. E., 1987. The runup of solitary waves, Journal of Fluid Mechanics., 185, 523-545.

11 Synolakis, C. E., Bernard, E. N., Titov, V. V., Kânoglu, U., González, F., 2008. Validation and 12 verification of tsunami numerical models, Pure Applied Geophysics, 165, 2197-2228.

13 Toda S., Lin, J., Stein, R. S., 2011. Using the 2011 Mw 9.0 off the Pacific coast of Tohoku 14 Earthquake to test the Coulomb stress triggering hypothesis and to calculate faults 15 brought closer to failure. Earth Planets Space, 63, 725-730.

16 USGS, 2011. Earthquake Information Bulletin: Magnitude 9.0, Near the East Coast of Honshu, Japan. U.S. Geological Survey, National Earthquake Information Center (available at

19 Wei, S., Sladen, A., 2011. Tohoku source model v.1 available at http://www.tectonics.caltech.edu/slip history/2011_taiheiyo-oki/, 2011.

21 Wilcox, D. C., 2000. Turbulence modeling for CFD. DCW Industries, Inc. 540pp. 
1 Yagi, Y., Fukahata, Y., 2011. Rupture process of the 2011 Tohoku-Oki earthquake and absolute elastic strain release. Geophysical Research Letter, 38, L19307, doi:10.1029/2011GL048701.

4 Yoon, B. S., Bae, J. S., Lim, C. H., 2011. Propagation characteristics of the Pacific coast of Tohoku tsunami in South Sea of Korea. The Pacific Ocean Tsunami (in Korean Language), Korean Society of Coastal and Ocean Engineers, Printed by Hanrimwon Co. Ltd, 48-52pp.

Zheng, L, Chen, C., Liu, H., 2003. A modeling study of the Satilla River Estuary, Georgia. Part I: flooding/drying process and water exchange over the salt marsh-estuary-shelf complex. Estuaries, 26 (3), 651-669.

1

12

13

4

15

6

.

8

9




\section{Figure Captions}

2 Figure 1 Location of the mainshock with epicenter at $38.30^{\circ} \mathrm{N}, 142.37^{\circ} \mathrm{E}$ at $5: 46 \mathrm{UTC}$ (local time at 14:46 PM) on March 11, 2011 (USGS, 2011), followed by a M7.9 aftershock on the eastern Japanese shelf (filled red dot); the regional circulation pattern (color vector lines); enlarged view of the Fukushima Dai-ichi Nuclear Power Plant (FDNPP) (upper-left) with heights of breakwaters and an adjacent image showing the damage of FDNPP facilities (downloaded from http://www.nytimes.com/interactive/2011/03/13/world/asia/satellitephotos-japan-before-and-after-tsumami.html); and the locations of eight coastal tide gauge stations from Kuji to Fukushima (green dots) used for the model-data comparisons (right-lower) in the Tōhoku region bounded by the white box.

Figure 2 Illustration of nested Global-JC FVCOM system. Blue line presents the nesting boundary between Global-FVCOM and JC-FVCOM. Left: Global-FVCOM grid; rightupper: JC-FVCOM grid; and right lower: enlarged view of the grid in the FDNPP. The horizontal resolution varies in range of 2 to $25 \mathrm{~km}$ for Global-FVCOM and $5 \mathrm{~m}$ to $5 \mathrm{~km}$ for JC-FVCOM.

Figure 3 Seafloor changes estimated based on five seismic rupture models of the March 11 M9.0 mainshock and M7.9 aftershock. Named as case-a for Wei and Sladen (2011) and Simons et al., (2001); case-b for Fujii et al. (2011); case-c for Shao et al. (2011); case-d for Pollitz et al. (2011), and case-e for Yagi and Fukahata (2011).

Figure 4 Distributions of near-surface circulation (vectors) and water temperature (color image) over the Japanese shelf at 5:00 UTC March 11, 2011. The earthquake occurred over the slope and western side of the Japan Trench in a region characterized by strong mesoscale variability of upper-ocean currents between the Kuroshio (on the south) and the Oyashio 
Current (on the north). At this specified time, the subtidal coastal currents over the shelf were northward.

Figure 5 Snapshots of the water level distribution (m) of the leading tsunami wave over the eastern Japanese shelf at 05:51:53, 06:15:03 and 06:42:23 (hours: minutes: seconds) UTC on March 11, 2011.

Figure 6 The distribution of the tsunami peak as it propagated towards the coast on March 11, 2011 (black line: hydrostatic; red line: non-hydrostatic;). Black and red dots are the locations where the wave speeds are calculated for hydrostatic and non-hydrostatic cases and values next to the dots are the wave speed values in $\mathrm{m} / \mathrm{s}$ for the hydrostatic case. The blue number was the time (units: hours: minutes: seconds) at which the tsunami peak was drawn. Heavy black line is the section selected to show the comparison of hydrostatic and non-hydrostatic results as the tsunami approached the FDNNP. The upper right panel is the enlarged view of the area around FDNPP bounded by a red box. Two blue lines indicate the north and south sections used to compare the model-predicted runup with analytical solutions.

Figure 7 Distribution of surface water currents before, during, and after the tsunami wave swept over the breakwaters of the FDNPP. The letter " $\mathrm{t}$ " denotes the time in minutes relative to the time at which the mainshock occurred. The vectors were plotted with a selection radius of $40 \mathrm{~m}$.

Figure 8 Time series of the water level at sites A and B (shown in the left-upper panel) during the tsunami. 
1 Figure 9 Comparisons of the model-simulated and observed sea level displacement (m) at eight tide gauges (location shown in Figure 1) over the initial 120-min period for the model runs with initial conditions of the seafloor change specified by case-a and case-c.

4 Figure 10 Comparisons of model-predicted inundation areas with the surveyed areas along the Miyagi coast (left panels) and in the FDNPP region (right panels) for the initial conditions of seafloor change specified by case-a.

Figure 11 Comparisons of snapshots of surface elevations (m) predicted by hydrostatic (black) and non-hydrostatic model runs at eight selected times relative to the time at which the mainshock occurred. The letter " $\mathrm{t}$ " denotes the time in minutes. Water depth (m) along the transect is shown in the bottom panel. The label "Site-C" indicates a location near the breakwater of FDNPP shown in Figure 6.

Figure 12 Distributions of the surface elevation (m) around the FDNPP region at two selected times before the inundation occurred for hydrostatic (left panels) and non-hydrostatic (right panels) cases.

Figure 13 Snapshots of the distributions of near-surface currents when the leading tsunami wave swept over FDNPP areas for hydrostatic (left panel) and non-hydrostatic (right panel) cases. The velocity scale is shown in the upper left of each panel.

Figure 14 Vertical profiles of sea temperature $\left({ }^{\circ} \mathrm{C}\right)$ at locations of the tsunami peak 26.5, 31.5 and 36.5 minutes after the earthquake happened for the cases with (red) and without (black) the tsunami.

Figure 15 Temperature sections $\left({ }^{\circ} \mathrm{C}\right)$ at the times $39.8,41.5$ and 43.2 minutes after the mainshock occurred for the cases without tsunami (right panel) and with the tsunamis predicted by non-hydrostatic (middle panel) and hydrostatic (left panel) models. Heavy white vertical 
lines in the center and left panels indicate the tsunami peak location at the first two times; the tsunami peak at the third time is located at the left side in these two panels. The values on the top are the time in minutes after the mainshock happened.

Figure 16 Comparisons of the model-predicted runup (black) with solitary wave (red) and $\mathrm{N}$ wave (blue) analytical solutions on the north section (left panels) and south section (right panels) shown as blue lines in Figure 6. The bottom panels show the water depth in units of $100 \mathrm{~m}$.

Figure 17 Snapshots of the surface elevation near the Miyagi coast at the times of 63.33, 64.17, 65.00 and 65.83 minutes after the mainshock occurred. Note: The high gradient contours seen in all snapshots in the region between land and sea are caused by the interpolation program and are not real. The red curves in the last three panels indicate the boundary of the reflected wave-induced relative uniform elevation zone.

Figure A1 Illustration of a cross-shelf section for an idealized coast with definition of $H$, and $h_{B}$.

Figure A2 Illustration of dry and wet segments of a tracer control element.

Figure B1 Comparisons of the model-simulated and observed sea level displacement (m) at eight tide gauges (location shown in Figure 1) over the initial 120-min period for the model runs with initial conditions of the seafloor change specified by case-b, case-d and case-e.

Figure B2 Comparisons of model-predicted inundation areas with the surveyed areas along the Miyagi coast for the initial condition cases of seafloor change specified by cases b-e. 
1 Figure B3 Comparisons of model-predicted inundation areas with the surveyed areas in the southern region of the Iwate coast for the five initial condition cases of seafloor change specified by cases a-e.

4 Figure B4. Comparisons of model-predicted inundation areas with the surveyed areas in the northern region of the Iwate coast for the five initial condition cases of seafloor change specified by cases a-e.

Figure B5 Comparisons of model-predicted inundation areas with the surveyed area in the 8 Fukushima Dai-ichi Nuclear Power Plant region for the initial condition cases of seafloor change specified by cases b-e. 
Table 1: Difference between observed and modeled main tsunami peaks and timings for the cases with initial seafloor change calculated using five seismic models.

\begin{tabular}{|c|c|c|c|c|c|c|c|c|c|c|}
\hline \multirow{2}{*}{ Station } & \multicolumn{2}{|c|}{ Case-a } & \multicolumn{2}{c|}{ Case-b } & \multicolumn{2}{c|}{ Case-c } & \multicolumn{2}{c|}{ Case-d } & \multicolumn{2}{c|}{ Case-e } \\
\cline { 2 - 12 } & $\begin{array}{c}\Delta \zeta \\
(\mathrm{m})\end{array}$ & $\begin{array}{c}\Delta t \\
(\mathrm{~min})\end{array}$ & $\begin{array}{c}\Delta \zeta \\
(\mathrm{m})\end{array}$ & $\begin{array}{c}\Delta t \\
(\mathrm{~min})\end{array}$ & $\begin{array}{c}\Delta \zeta \\
(\mathrm{m})\end{array}$ & $\begin{array}{c}\Delta t \\
(\mathrm{~min})\end{array}$ & $\begin{array}{c}\Delta \zeta \\
(\mathrm{m})\end{array}$ & $\begin{array}{c}\Delta t \\
(\mathrm{~min})\end{array}$ & $\begin{array}{c}\Delta \zeta \\
(\mathrm{m})\end{array}$ & $\begin{array}{c}\Delta t \\
(\mathrm{~min})\end{array}$ \\
\hline North Iwate & 2.09 & 1.01 & 1.57 & -5.59 & 0.55 & -3.43 & 2.41 & -5.73 & 2.67 & -7.52 \\
\hline $\begin{array}{c}\text { Central } \\
\text { Iwate }\end{array}$ & 2.45 & 4.68 & 3.01 & -0.97 & 2.27 & 1.18 & 3.84 & 6.01 & 4.35 & 8.65 \\
\hline South Iwate & 3.45 & 2.27 & 2.86 & 0.61 & -0.46 & 1.45 & 3.87 & 6.76 & 3.83 & 9.58 \\
\hline $\begin{array}{c}\text { North } \\
\text { Miyagi }\end{array}$ & 2.25 & -0.83 & 1.58 & 0.69 & -5.22 & 0.54 & 2.79 & 8.67 & 2.78 & 7.12 \\
\hline $\begin{array}{c}\text { Central } \\
\text { Miyagi }\end{array}$ & -0.72 & -1.29 & -3.81 & 0.38 & -10.54 & -0.79 & 1.70 & 7.52 & 4.19 & 2.85 \\
\hline $\begin{array}{c}\text { Sendai New } \\
\text { Port }\end{array}$ & -1.49 & -1.52 & -0.10 & -4.35 & -2.28 & 0.13 & -0.19 & 1.14 & 2.31 & 1.85 \\
\hline Fukushima & -1.67 & 3.29 & 0.25 & -4.69 & 0.98 & -3.90 & 0.69 & 6.77 & -5.35 & 5.78 \\
\hline
\end{tabular}

Note: Red values denote best-fitting models.

4

Table 2: Comparison between model-predicted and measured inundation areas.

\begin{tabular}{|c|c|c|c|c|}
\hline Types & $\begin{array}{c}\text { FDNPP } \\
\left(\mathrm{km}^{2}\right)\end{array}$ & $\begin{array}{c}\text { Region-I } \\
\left(\mathrm{km}^{2}\right)\end{array}$ & $\begin{array}{c}\text { Region-II } \\
\left(\mathrm{km}^{2}\right)\end{array}$ & $\begin{array}{c}\text { Sum (I and II) } \\
\left(\mathrm{km}^{2}\right)\end{array}$ \\
\hline Measured & 0.04 & 32.89 & 4.47 & 37.35 \\
\hline Case-a & 0.04 & 26.99 & 3.77 & 30.76 \\
\hline Case-b & 0.03 & 28.94 & 3.42 & 32.36 \\
\hline Case-c & 0.04 & 30.99 & 6.15 & 37.14 \\
\hline Case-d & 0.03 & 26.87 & 3.51 & 30.38 \\
\hline Case-e & 0.04 & 20.39 & 2.88 & 23.52 \\
\hline
\end{tabular}

6 Note: Region-I is located within longitudes from $140.84^{\circ} \mathrm{E}$ to $141.55^{\circ} \mathrm{E}$ and latitudes from $37.82^{\circ} \mathrm{N}$ to $38.6^{\circ} \mathrm{N}$.

7 Region-II is located within longitudes from $141.47^{\circ} \mathrm{E}$ to $142.12^{\circ} \mathrm{E}$ and latitudes from $38.74^{\circ} \mathrm{N}$ to $39.75^{\circ}$. Red values

8 denote best-fitting models. Case-c provides the best overall fit with the combined measurements. 


\section{FIGURES}

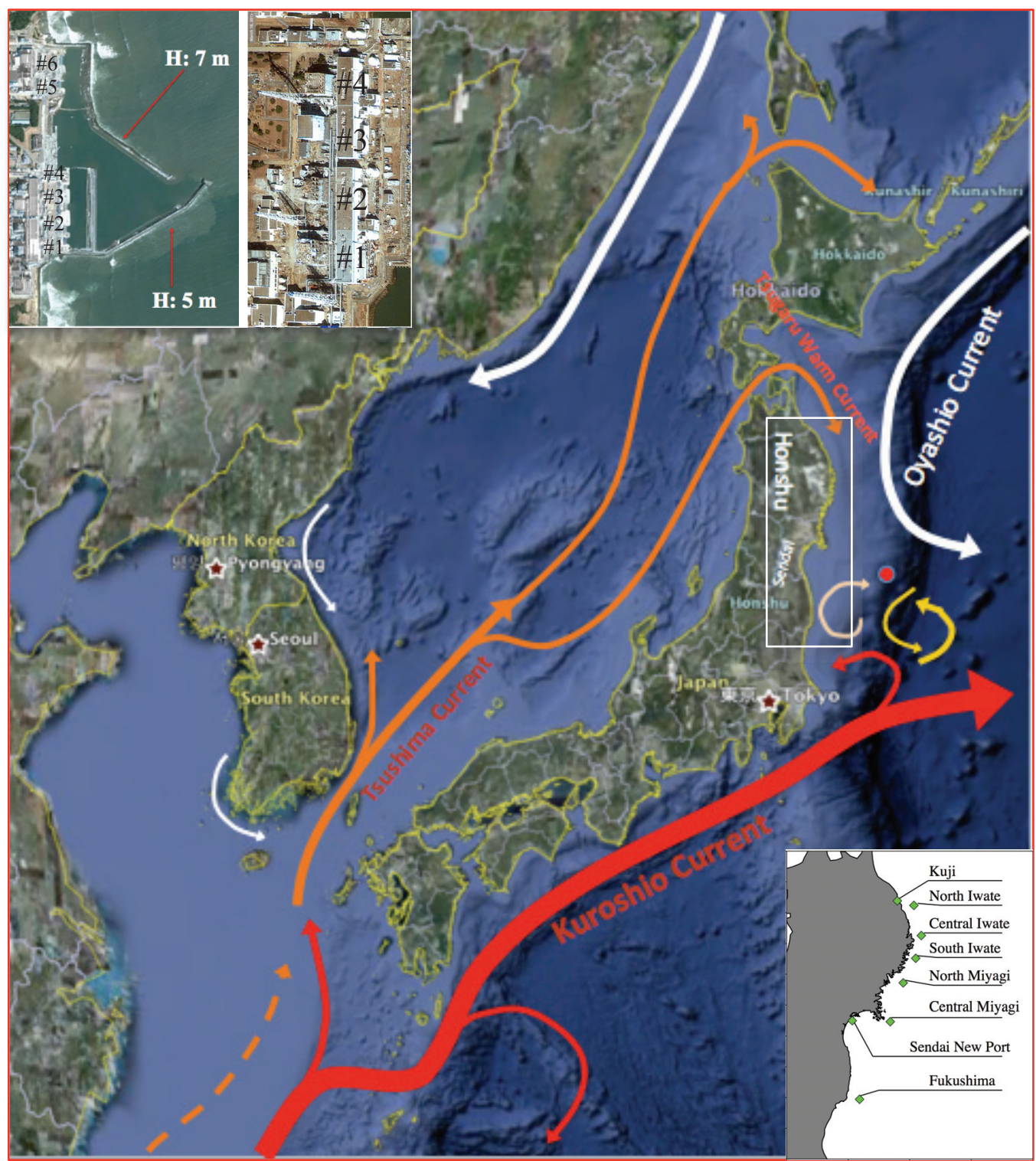

Fig. 1 
FVCOM Global-RegionalCoastal Nesting System

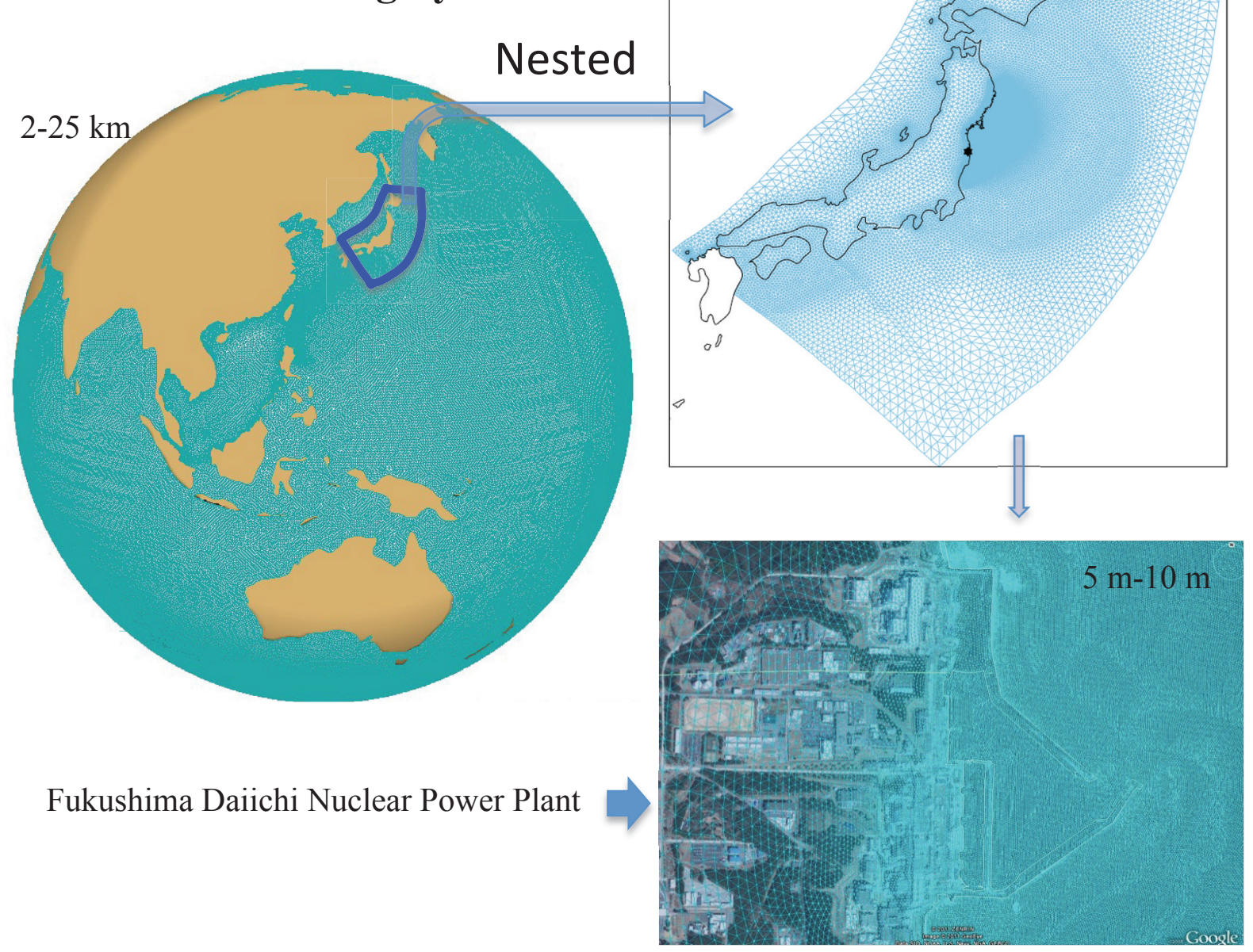

Fig.2 

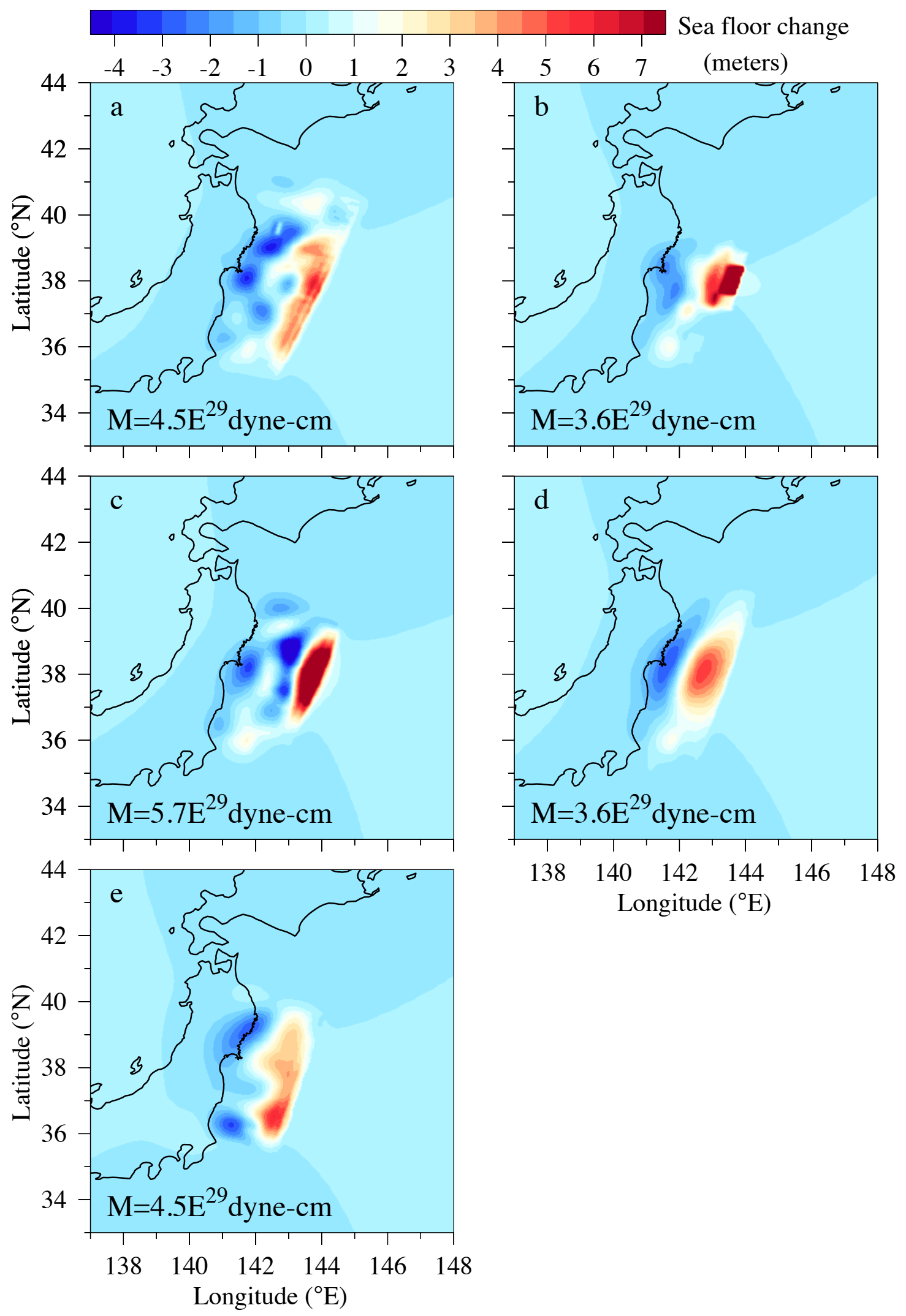

Fig.3 


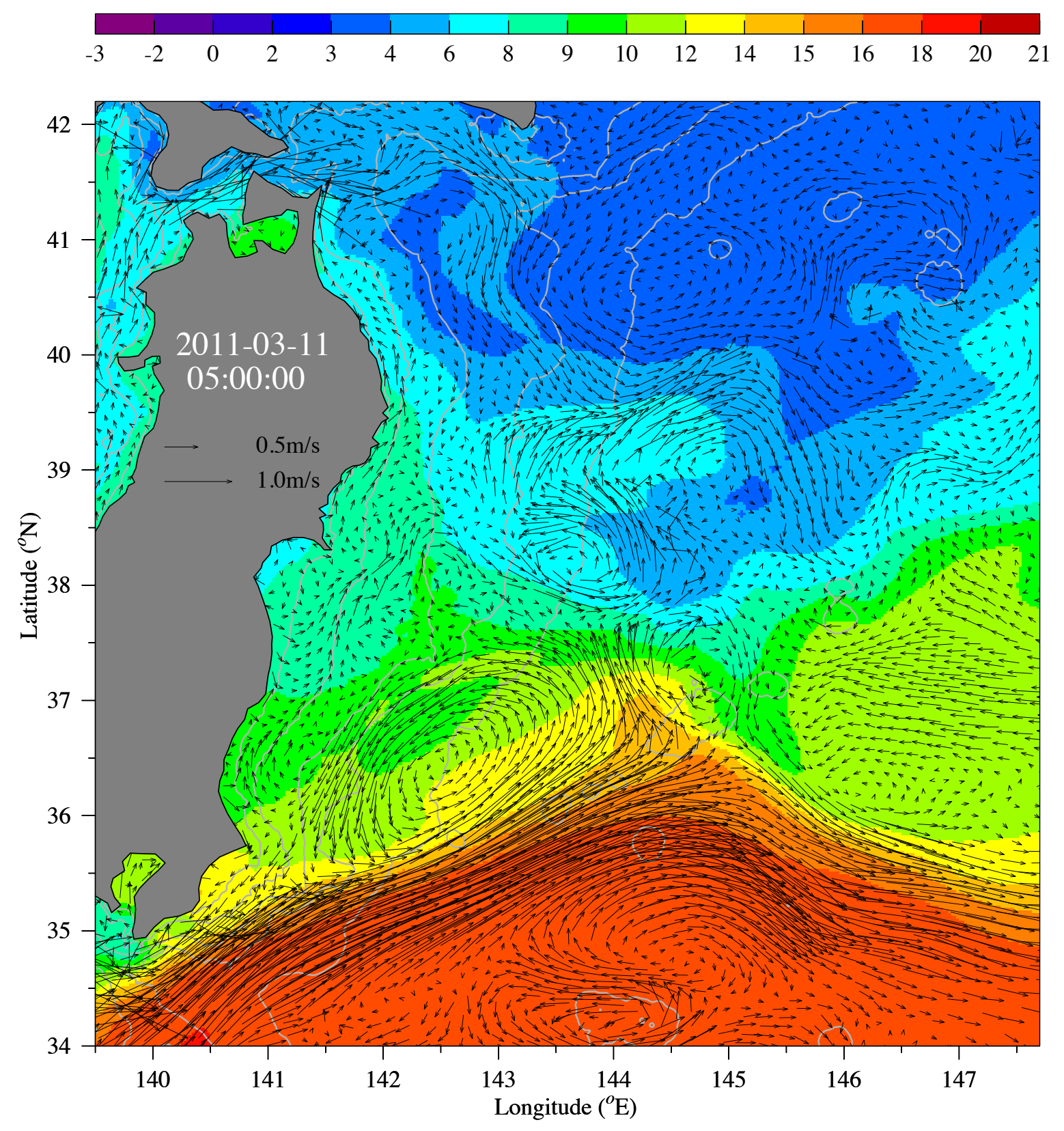

Fig. 4 

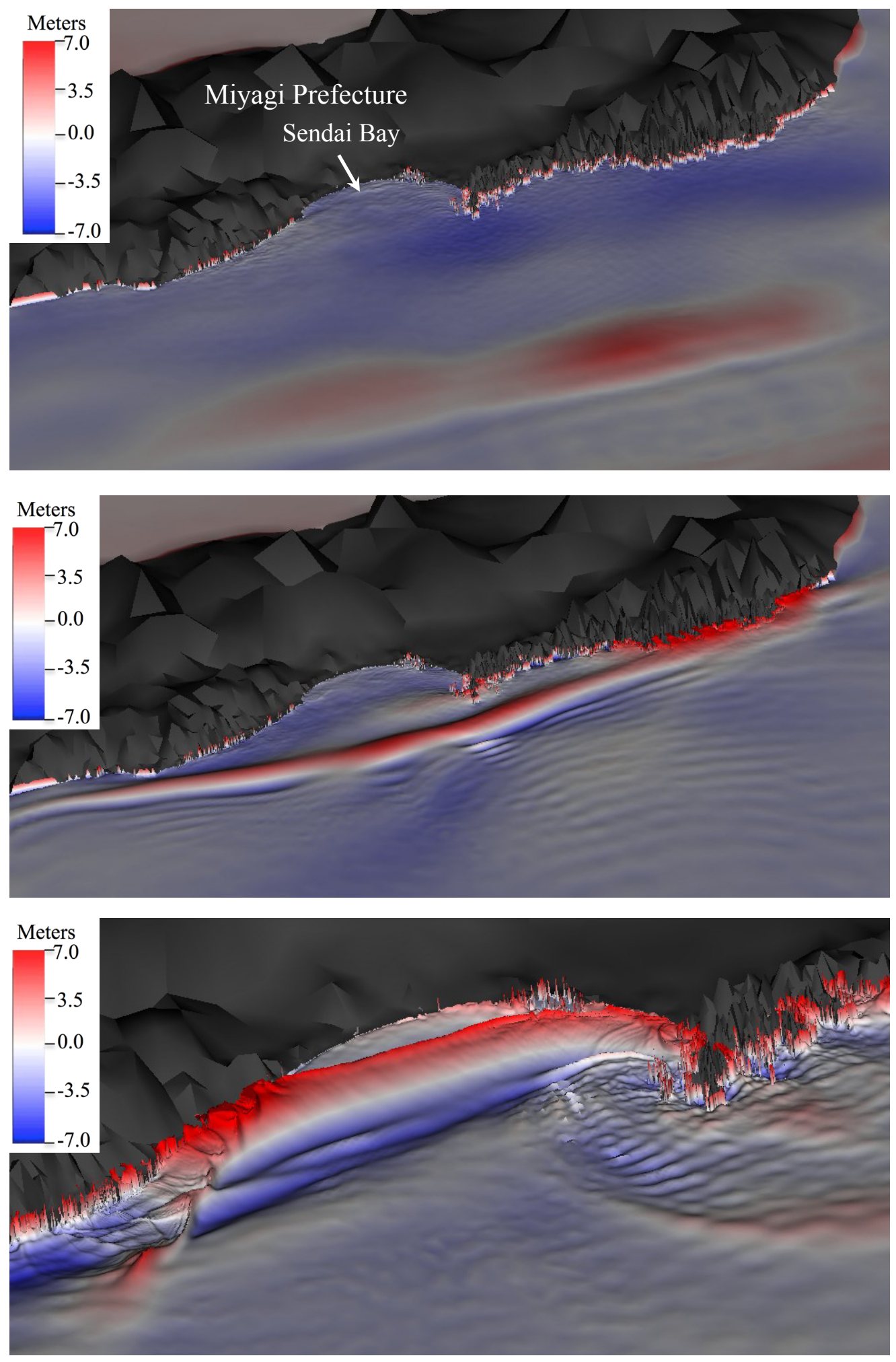

Fig. 5 


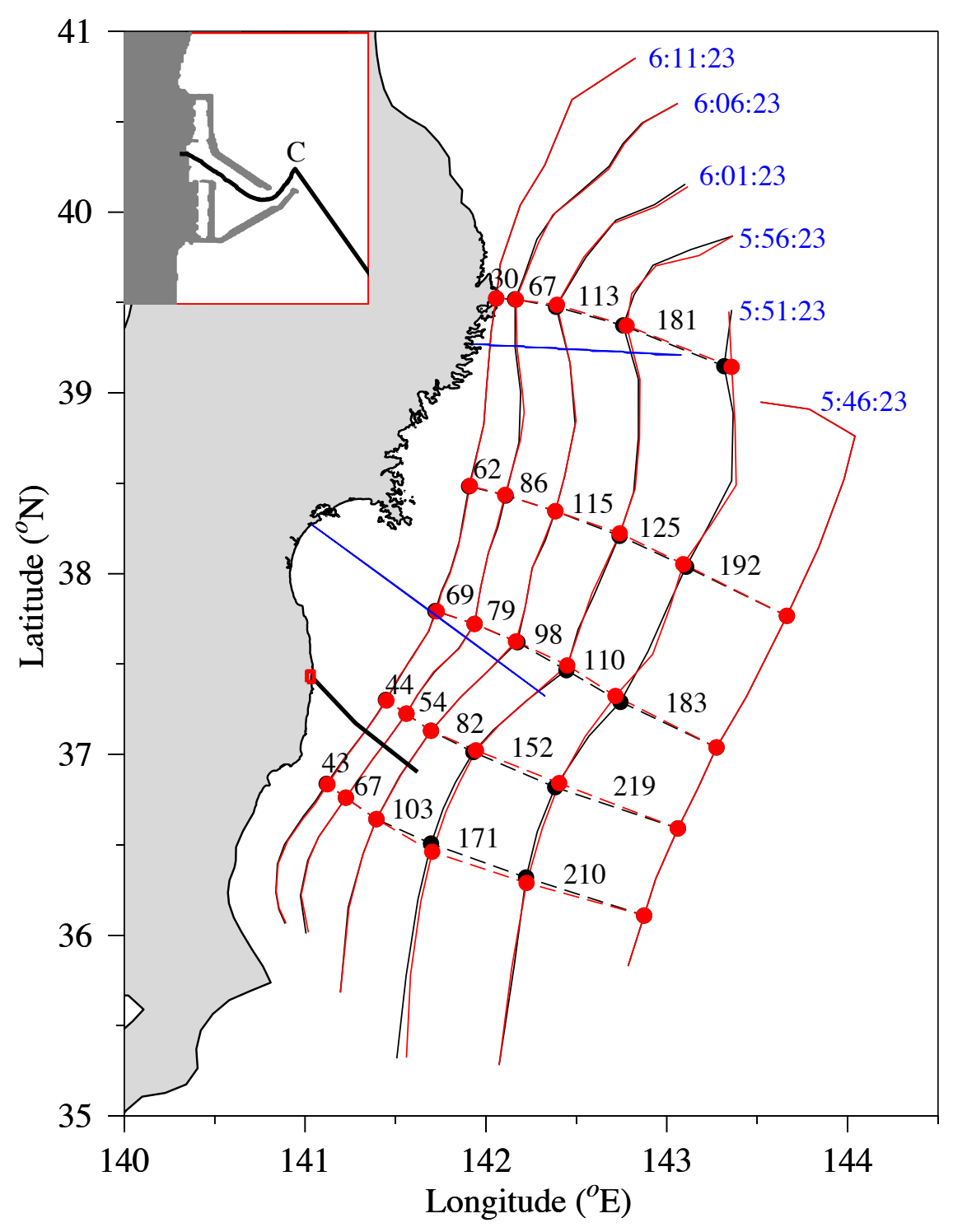

Fig.6 

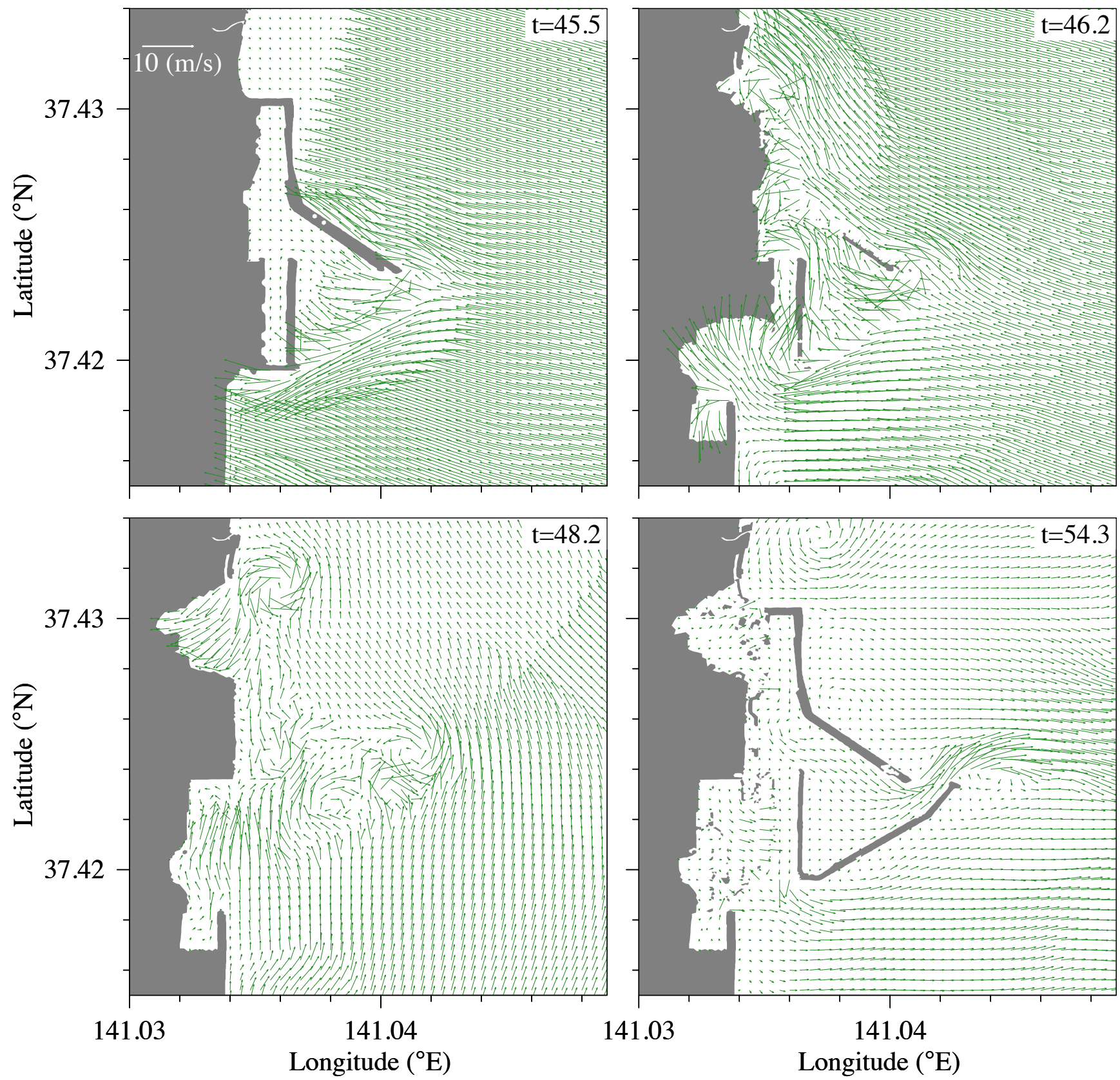

Fig. 7 


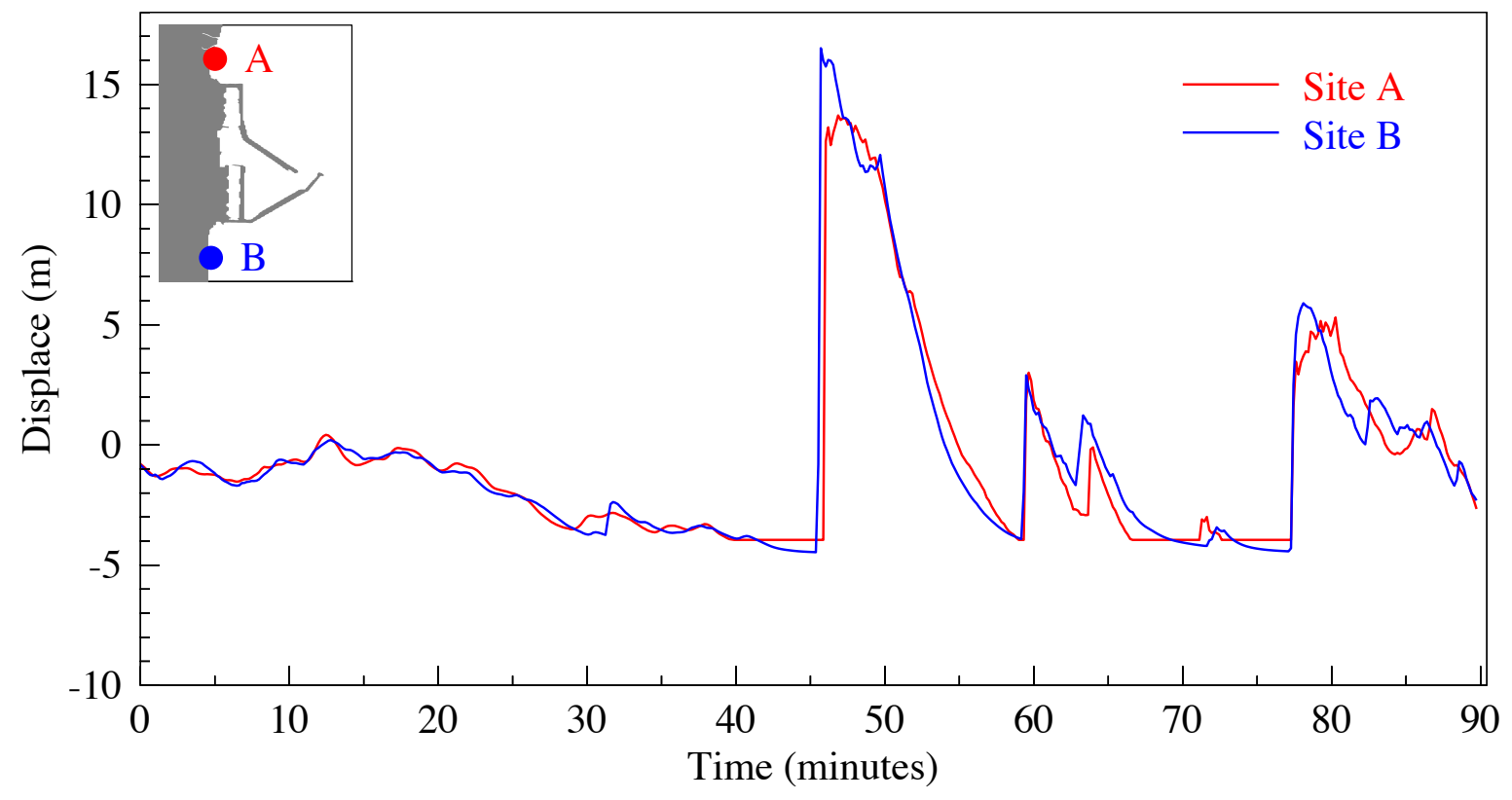

Fig.8 

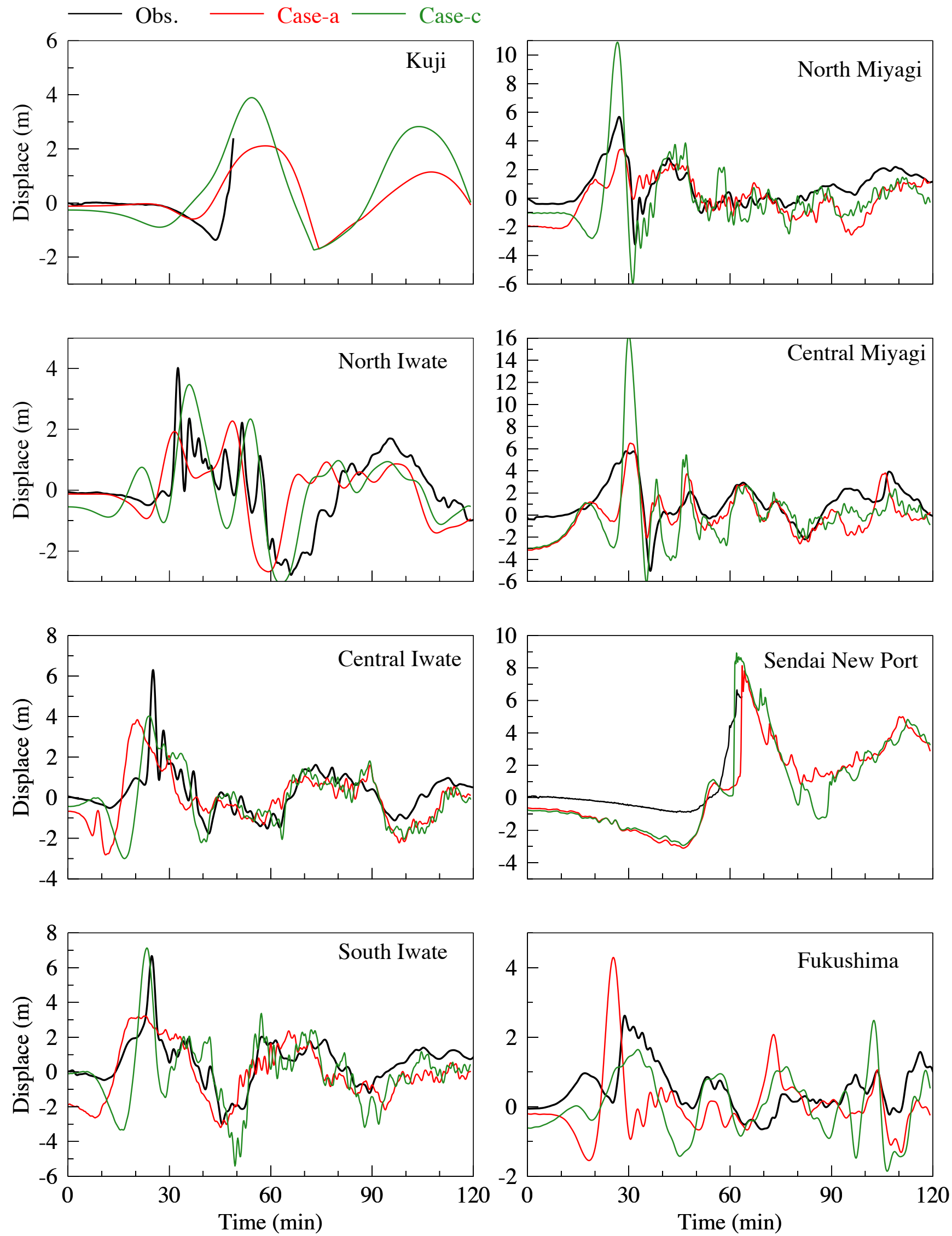

Fig.9 

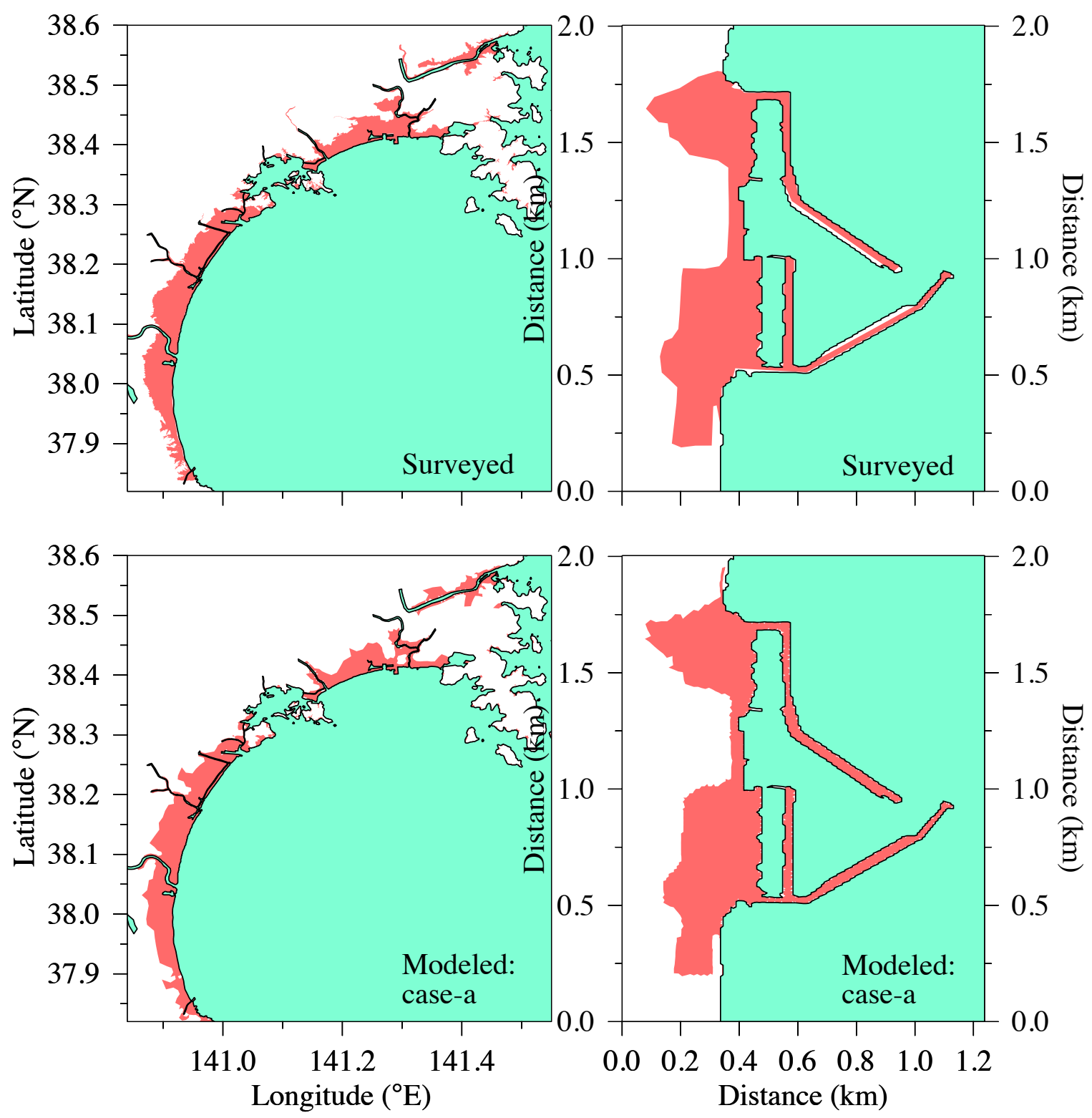

Fig.10 

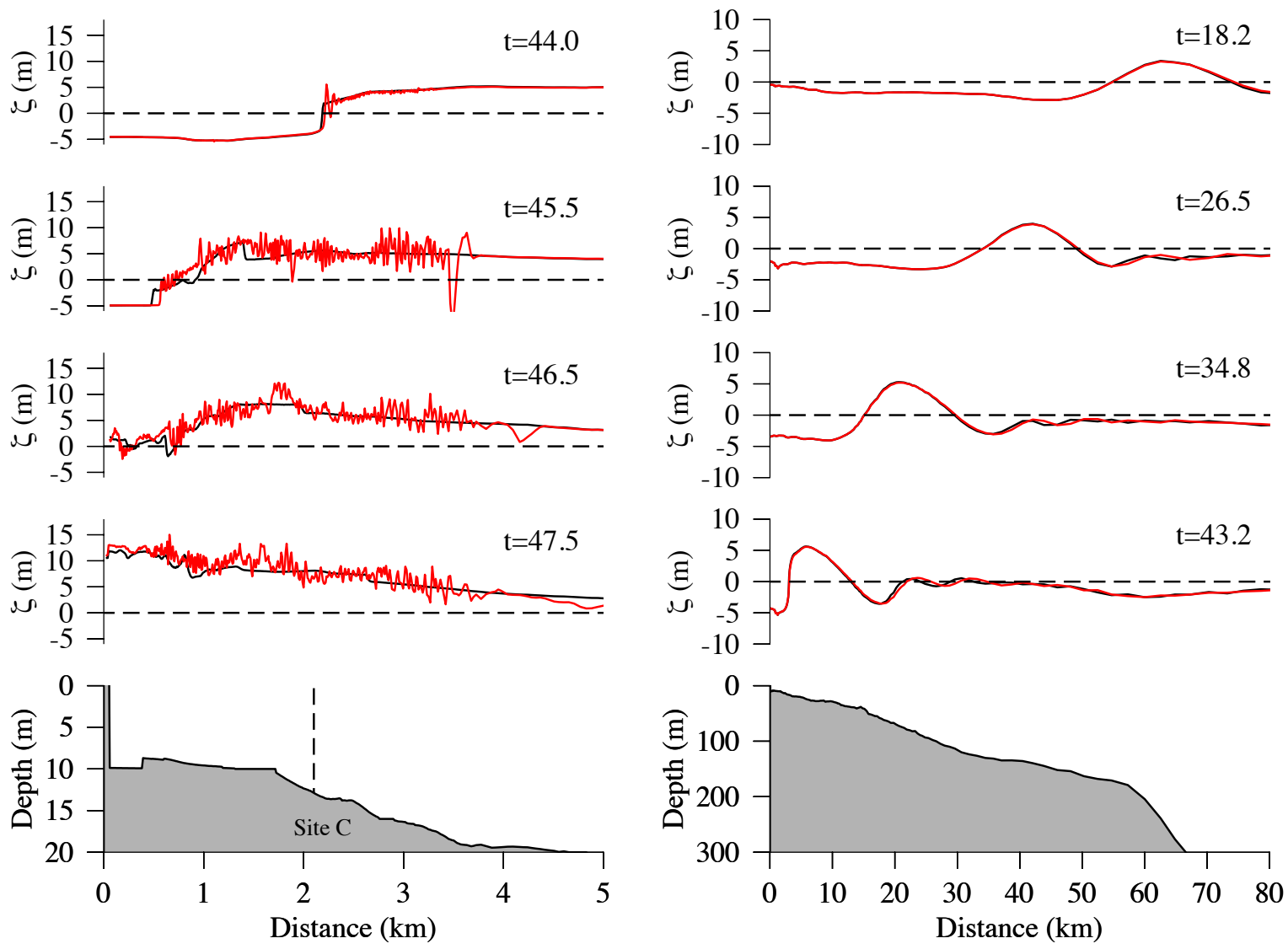

Fig.11 

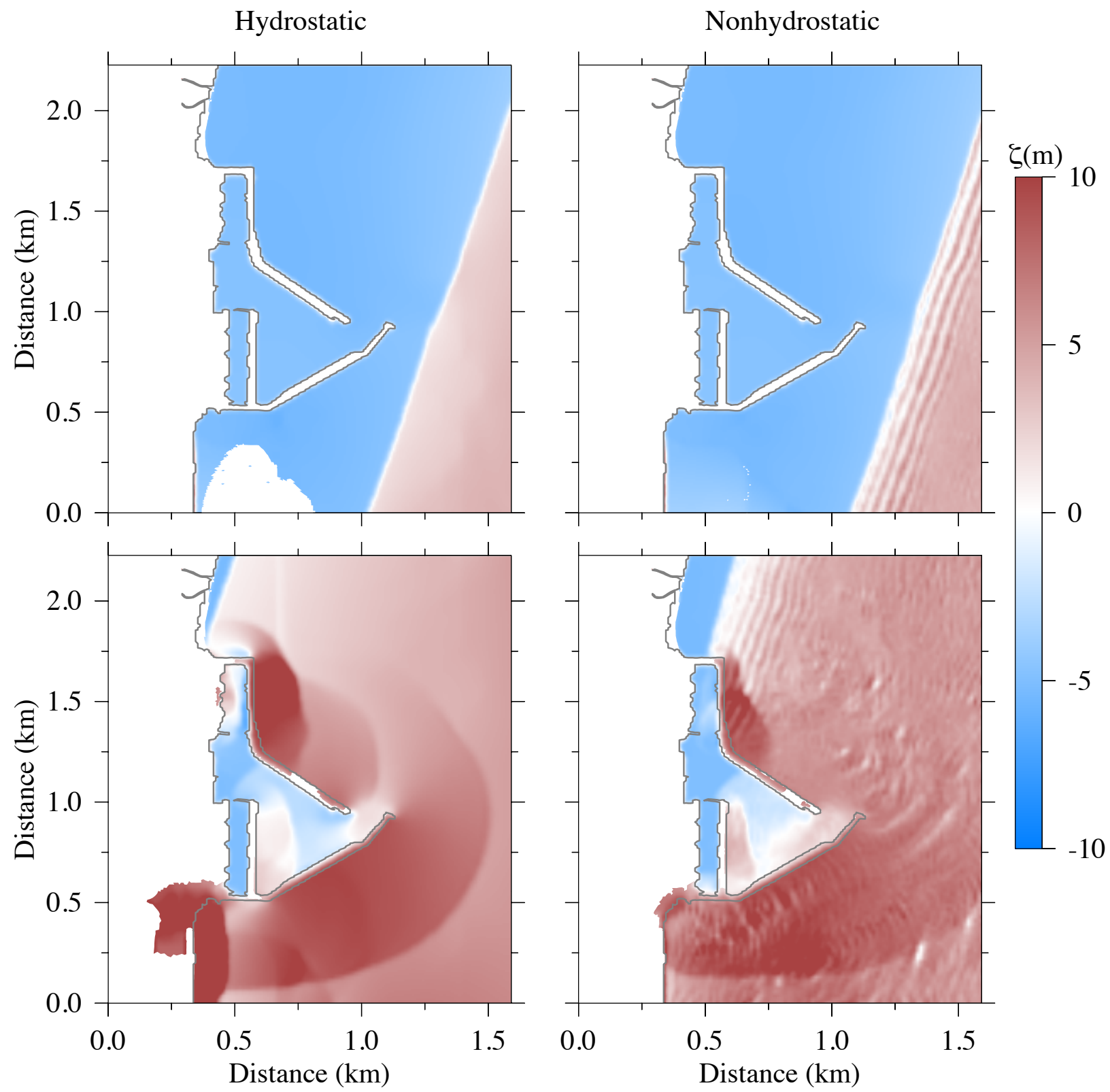

Fig.12 

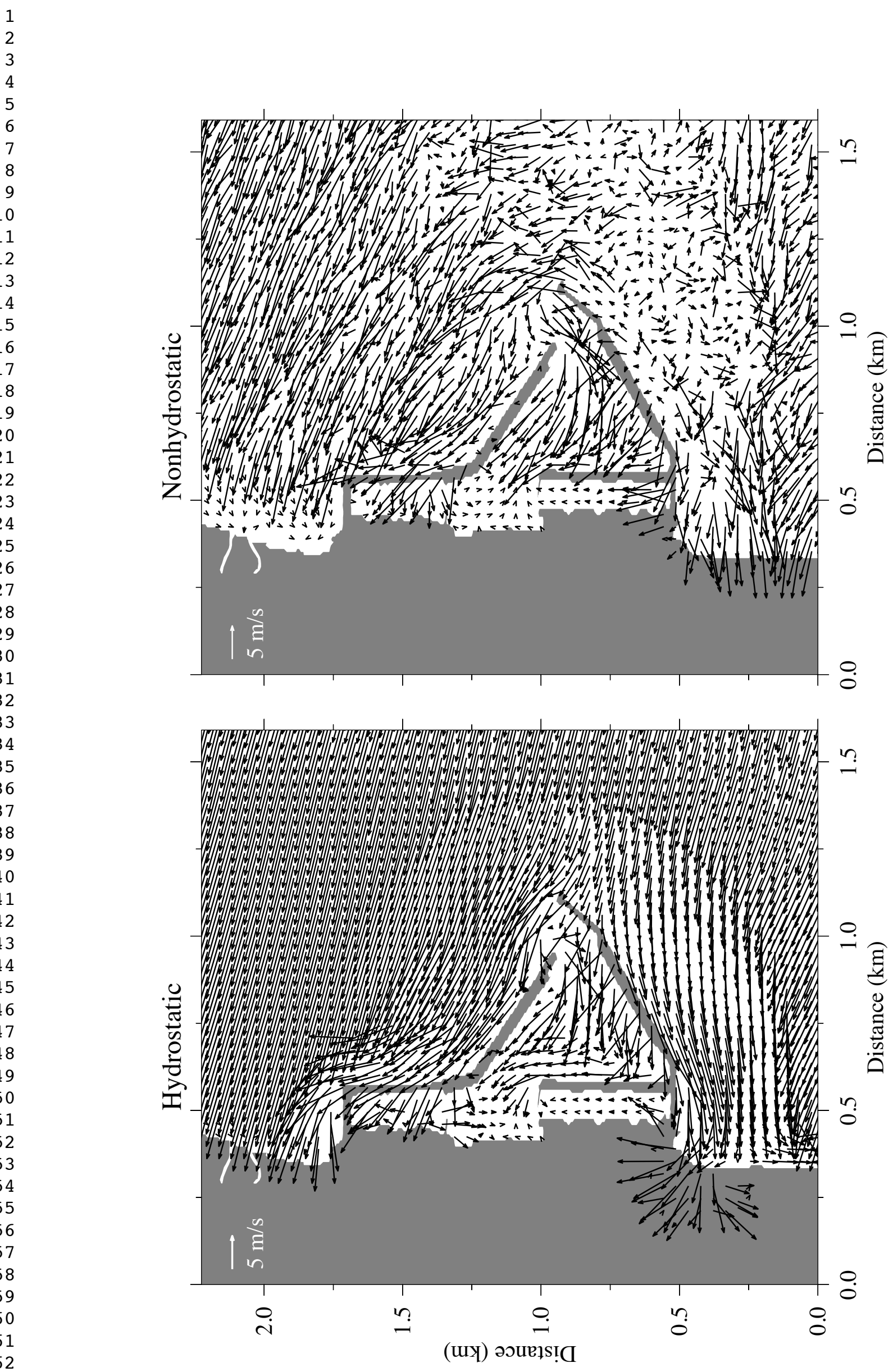

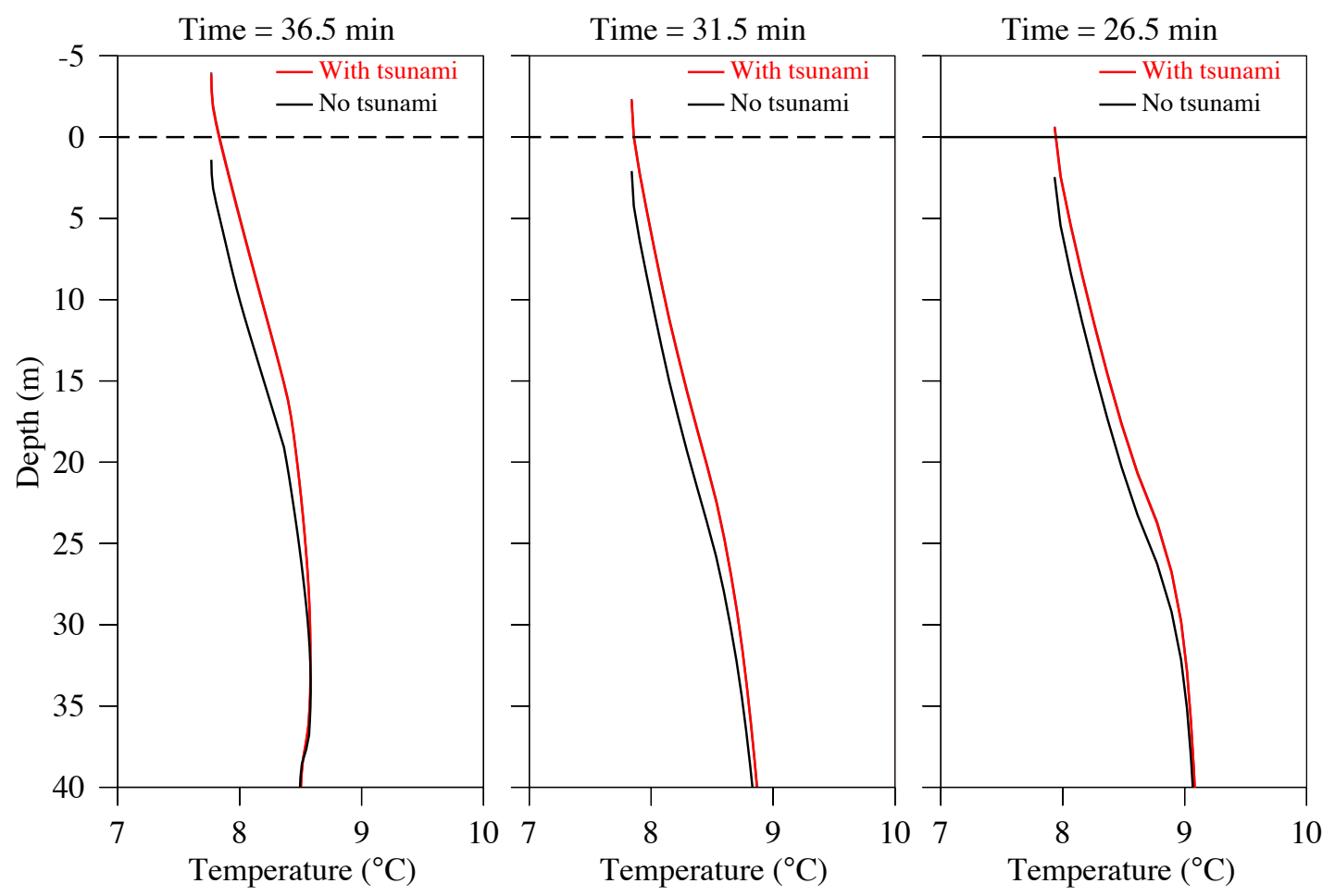


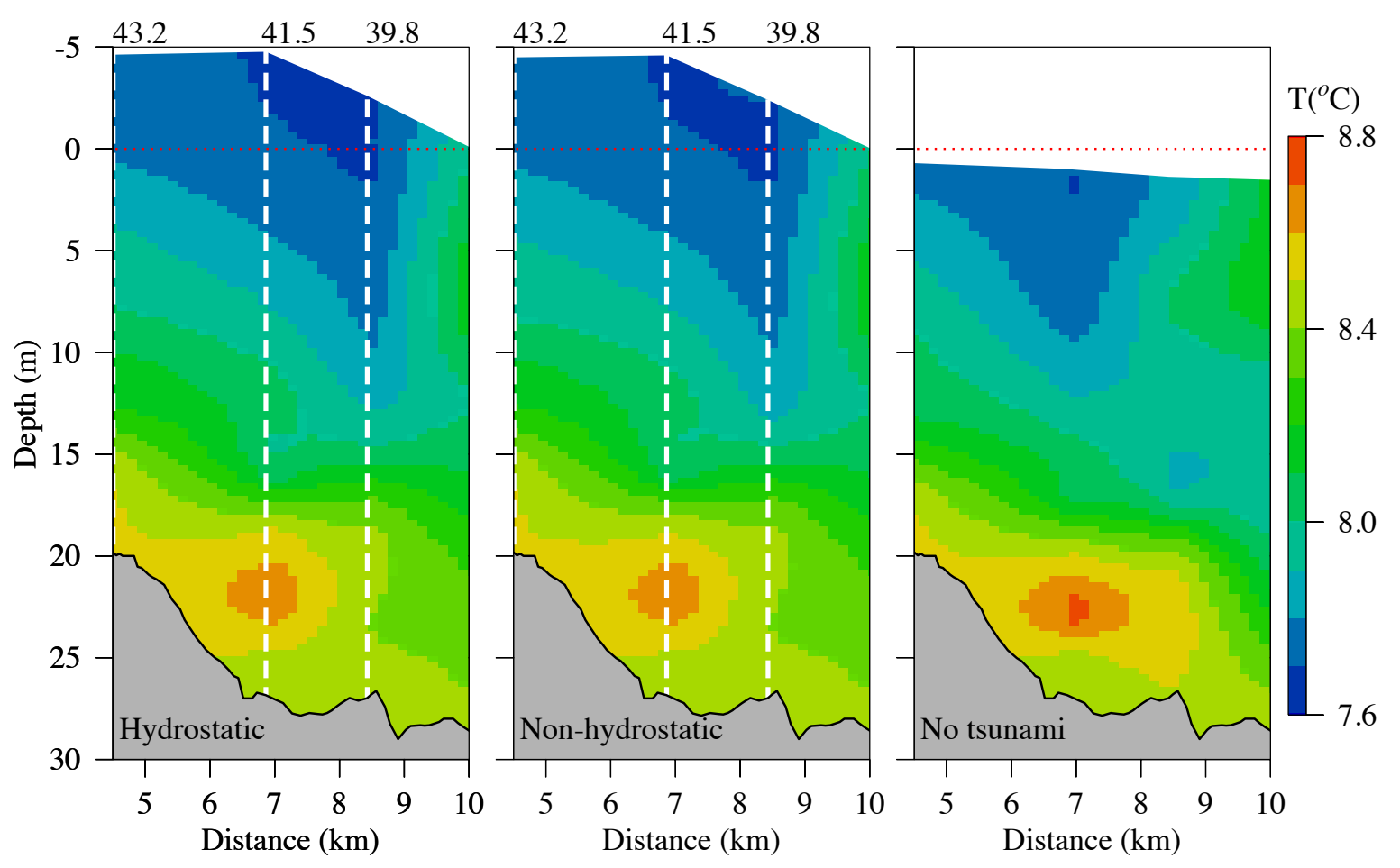

Fig.15 


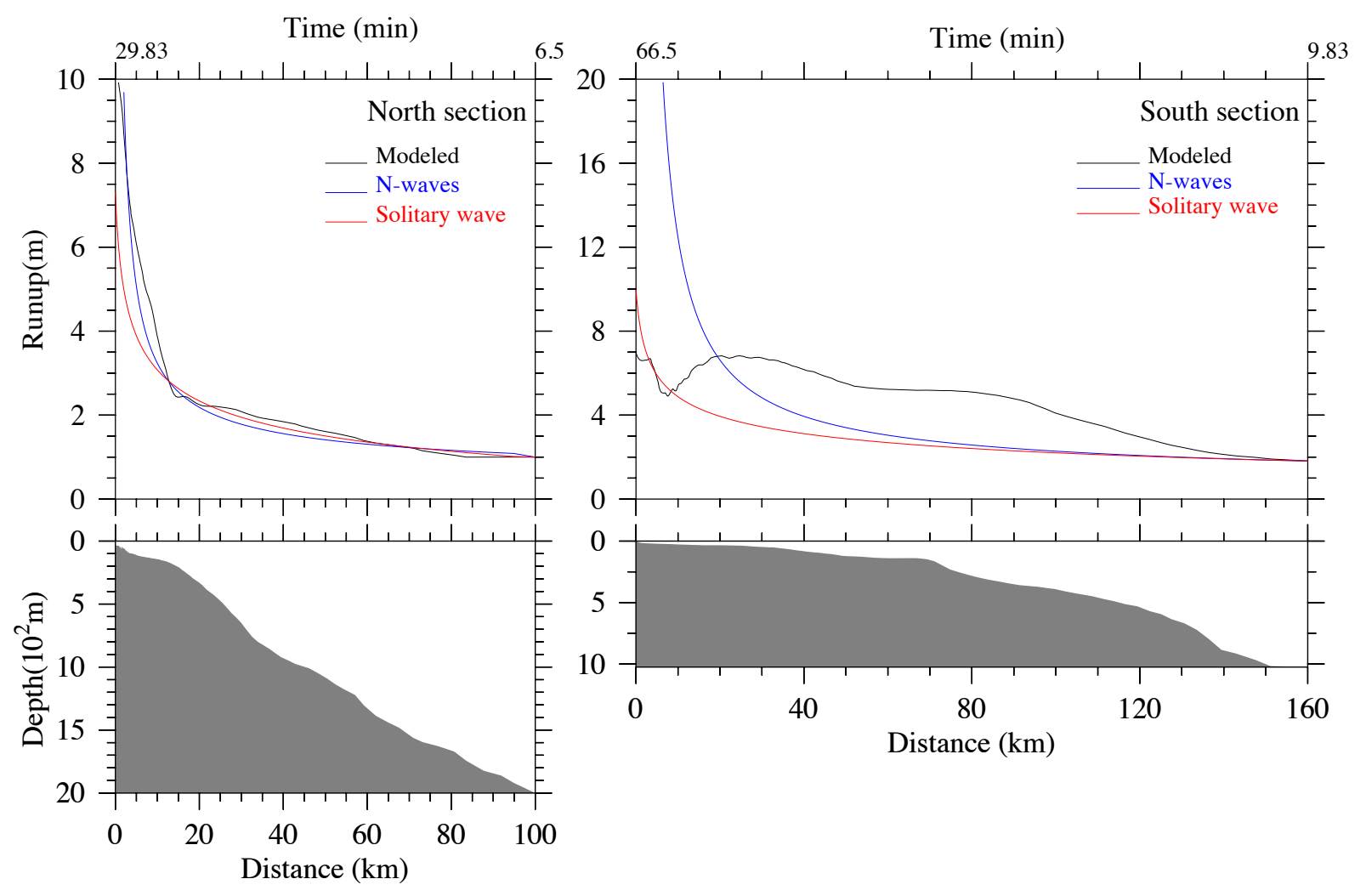

Fig. 16 

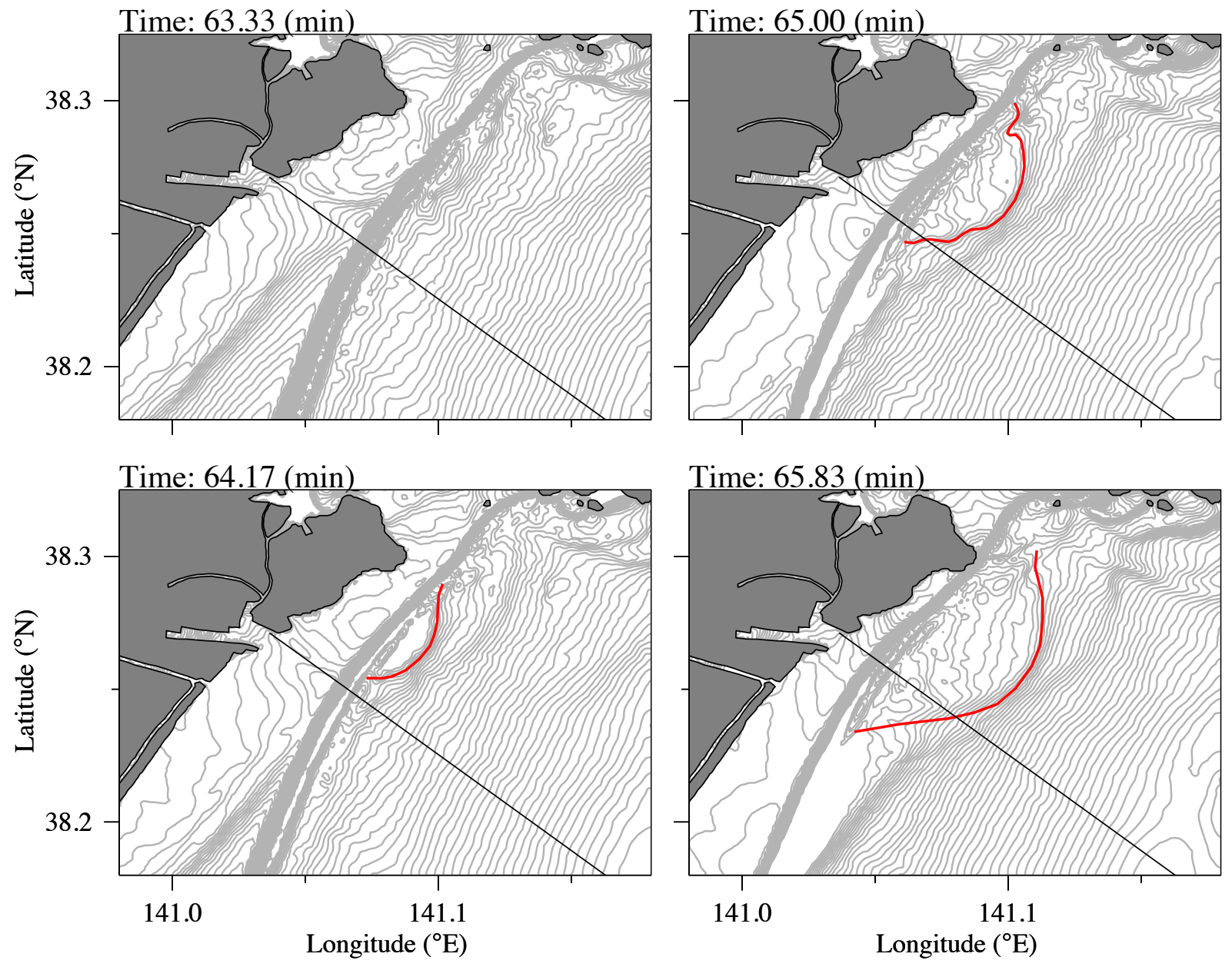


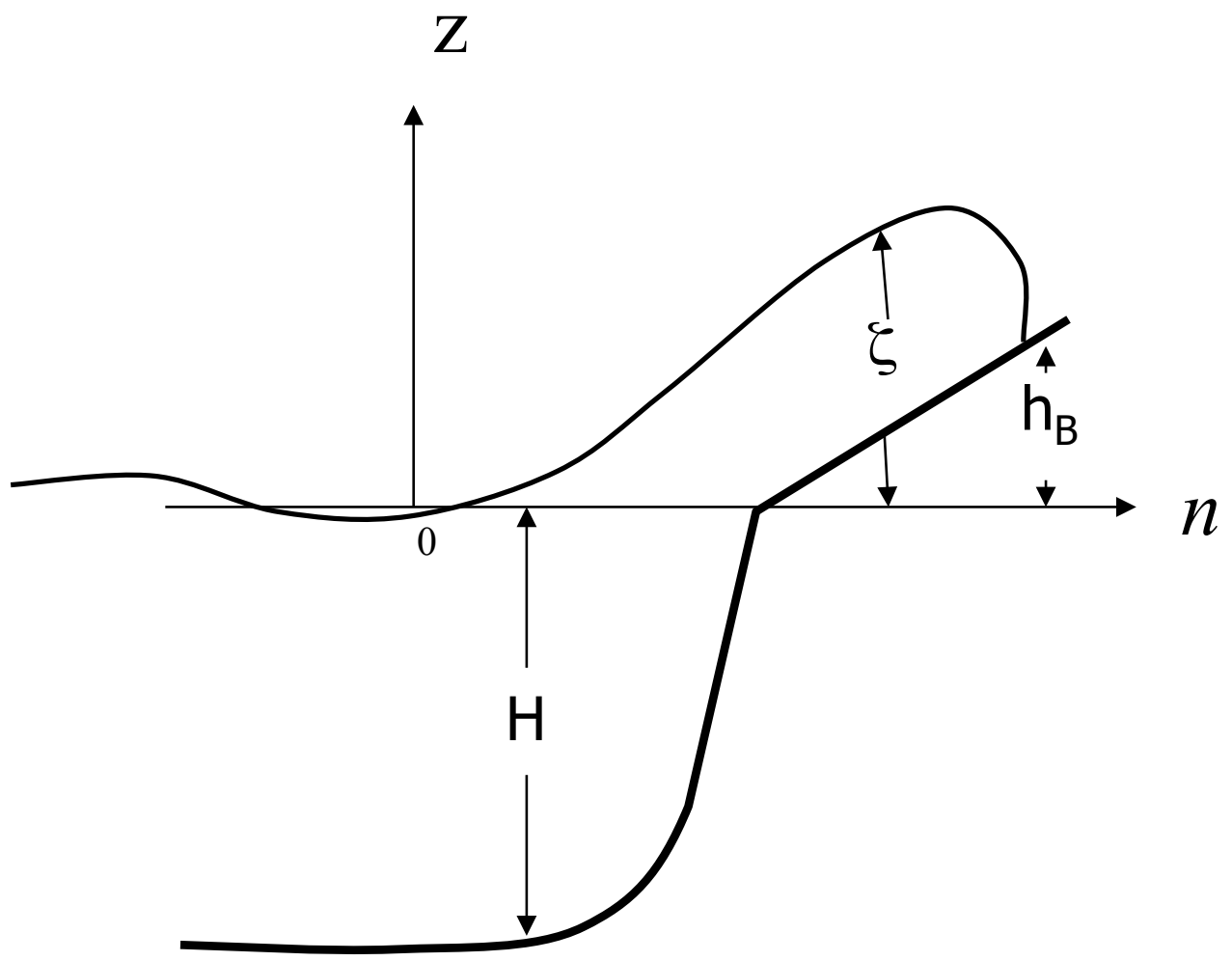

Fig. A1 


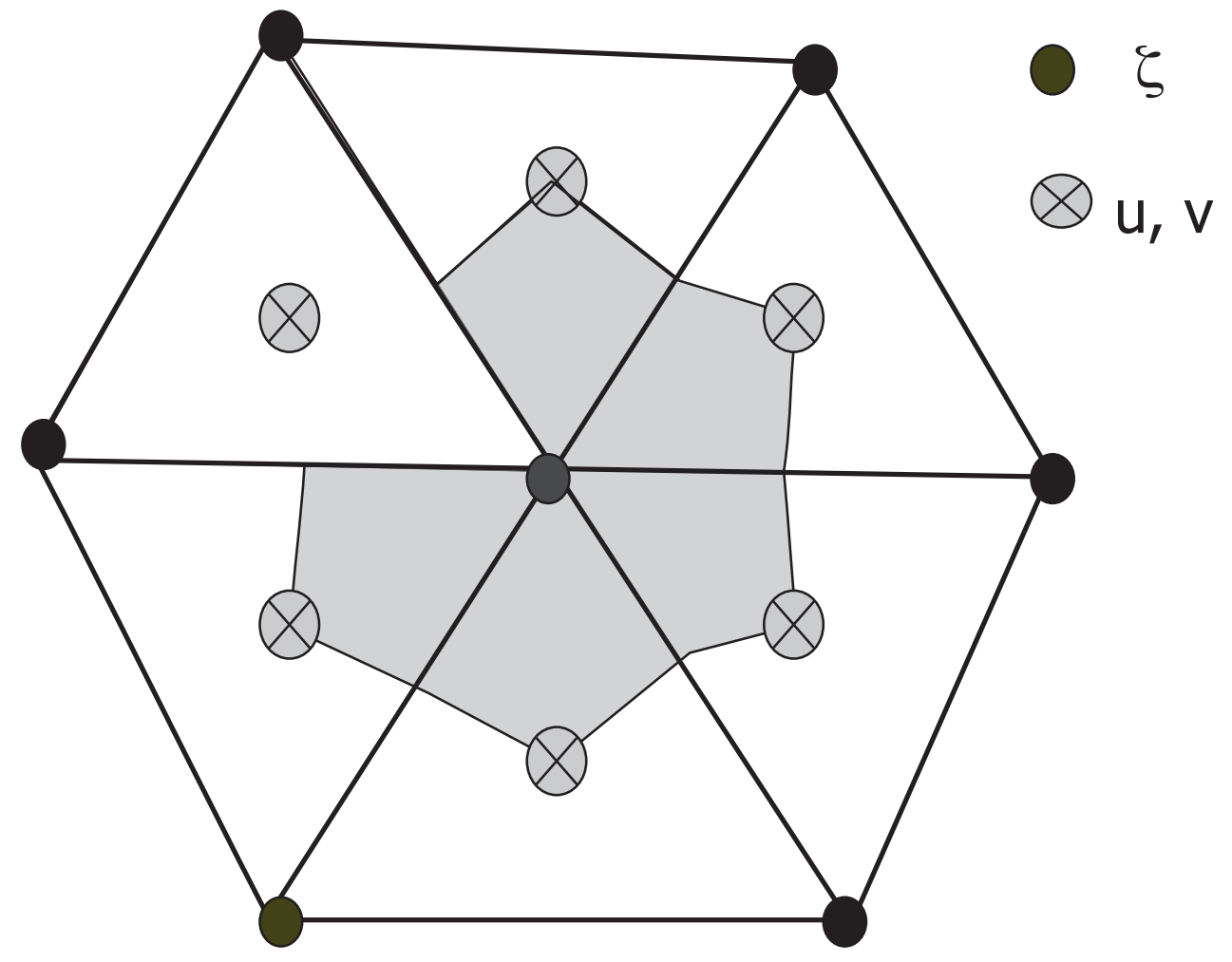

Fig. A2 


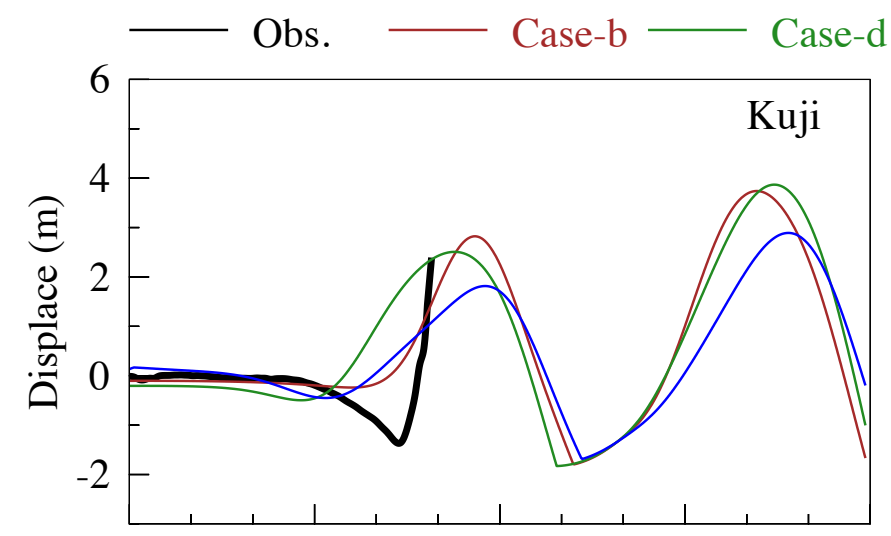

- Case-e
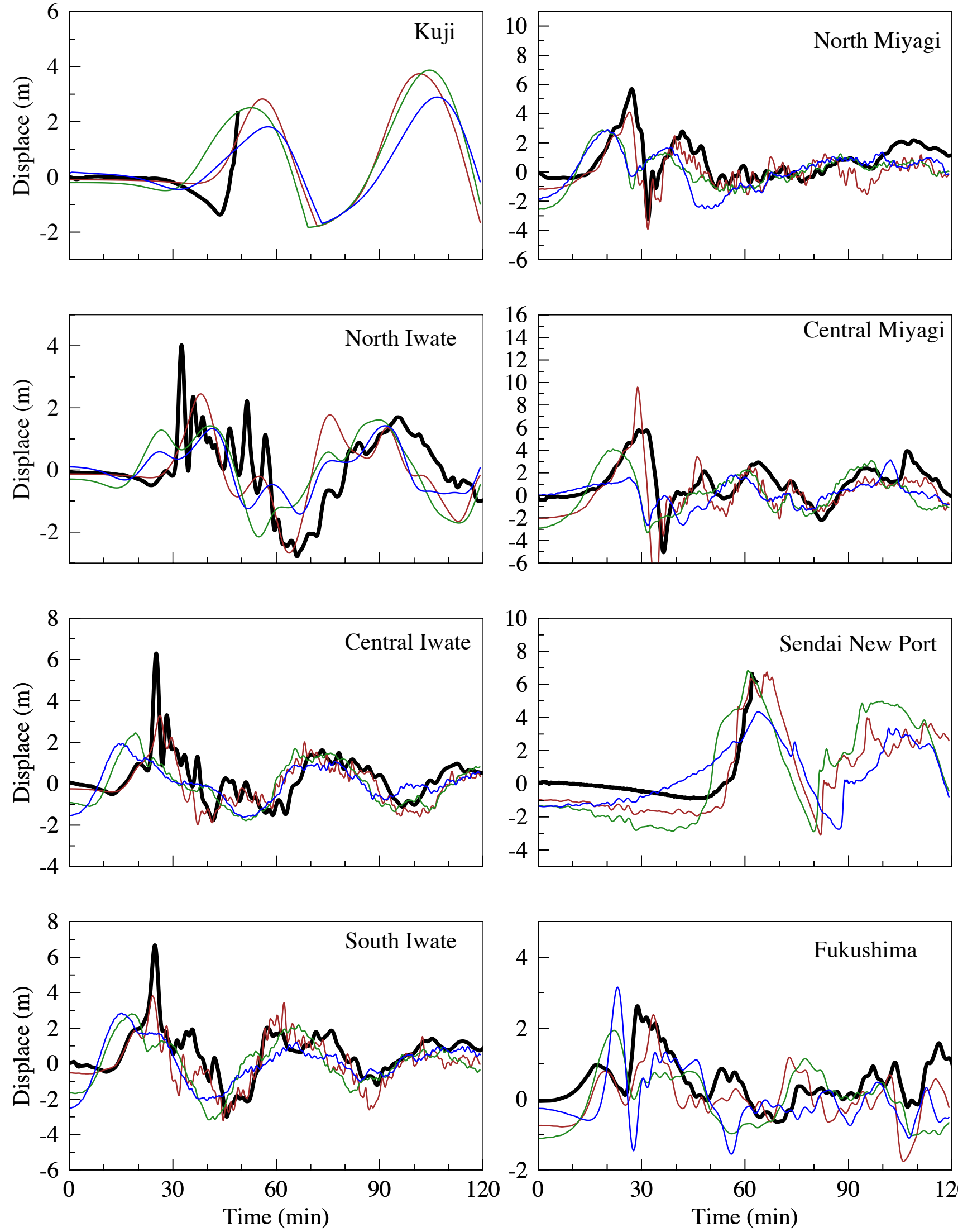

Fig.B1

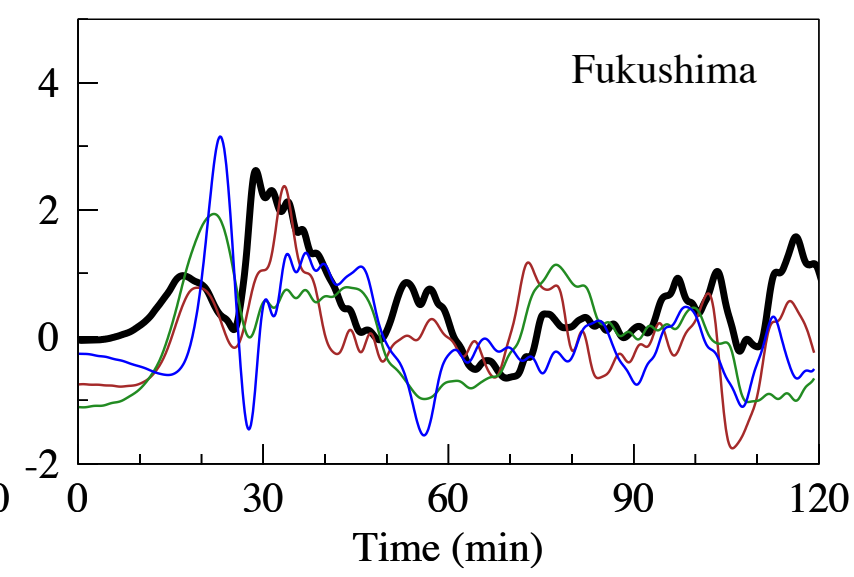



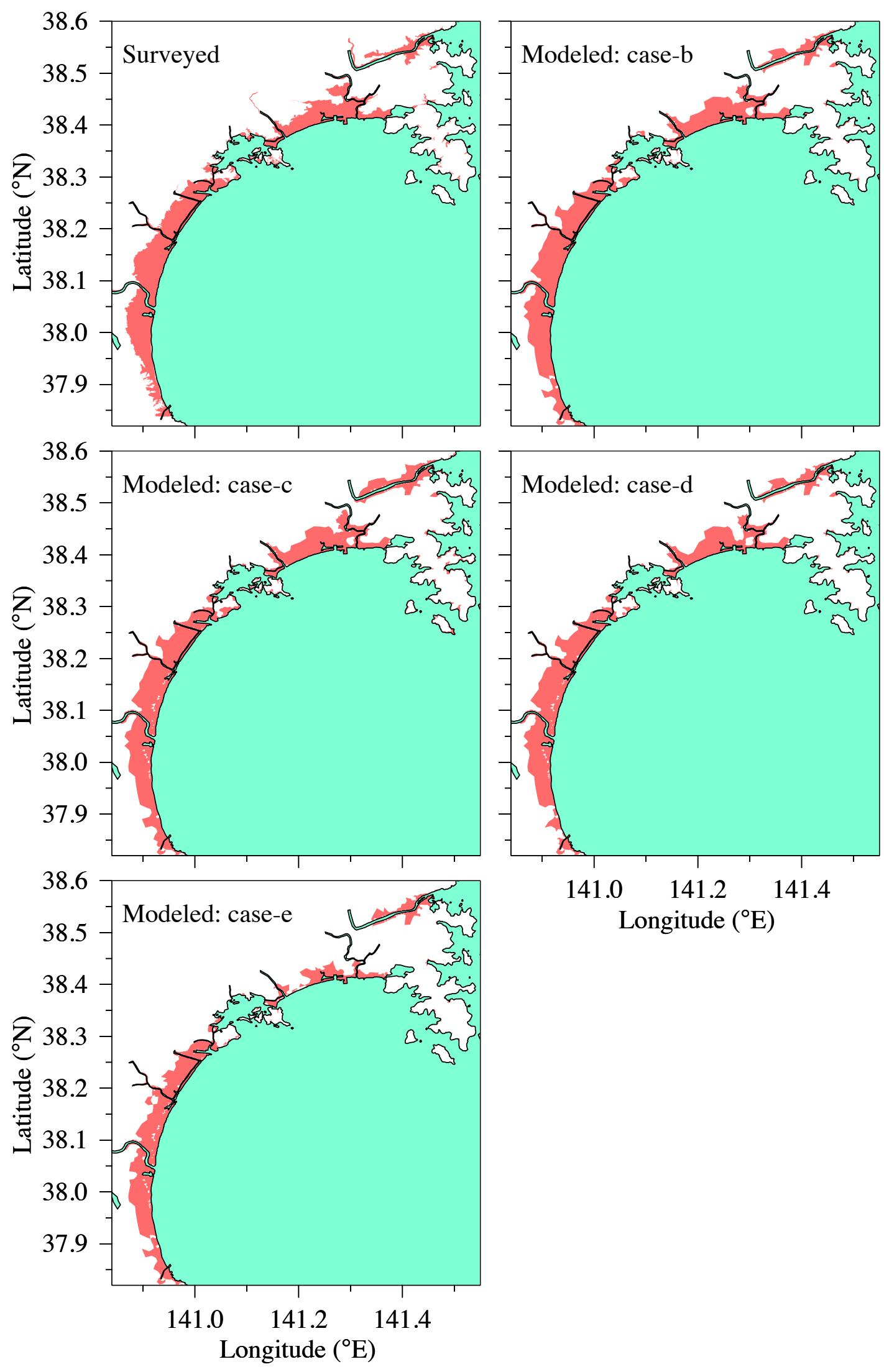

Fig.B2 

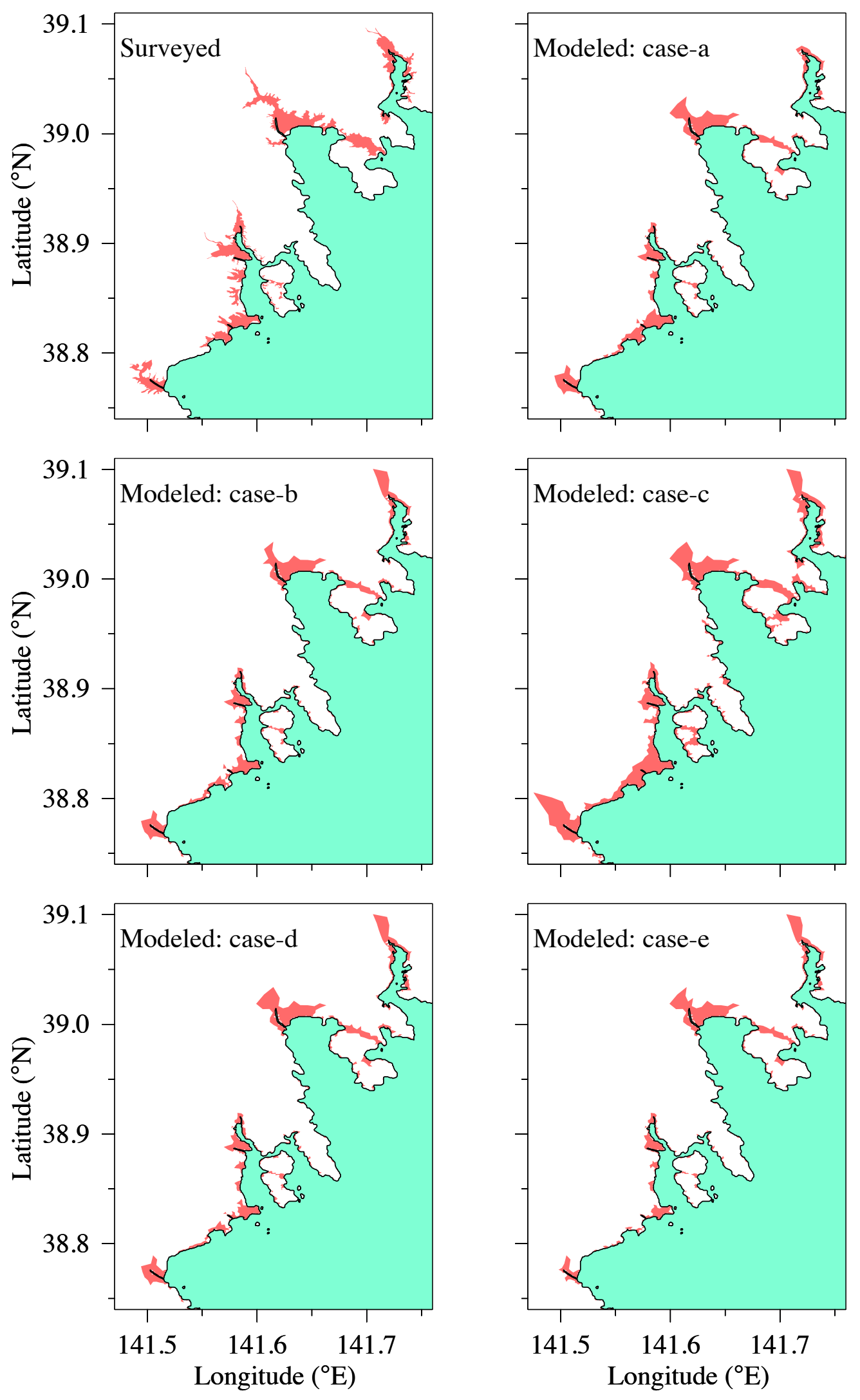

Fig.B3 

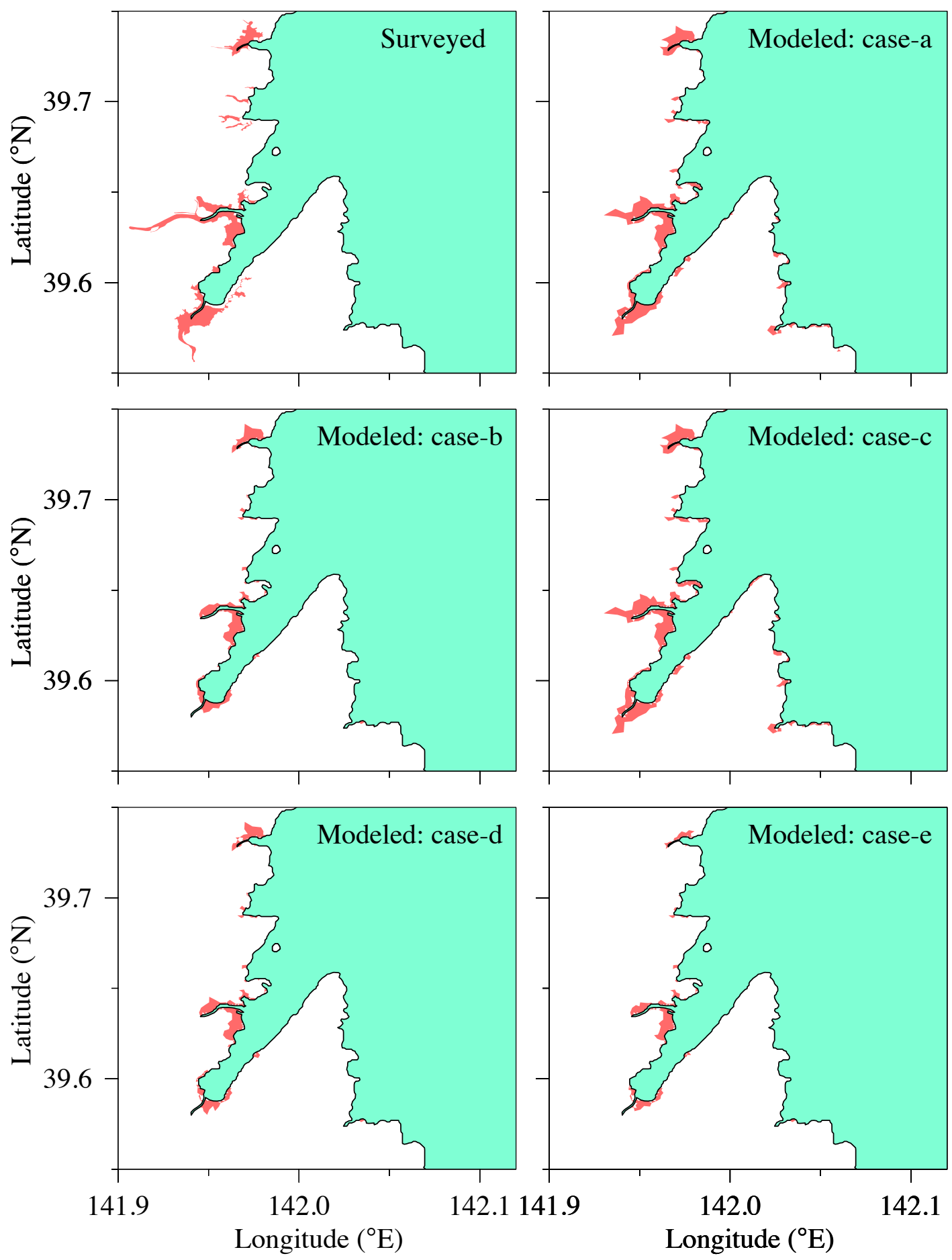


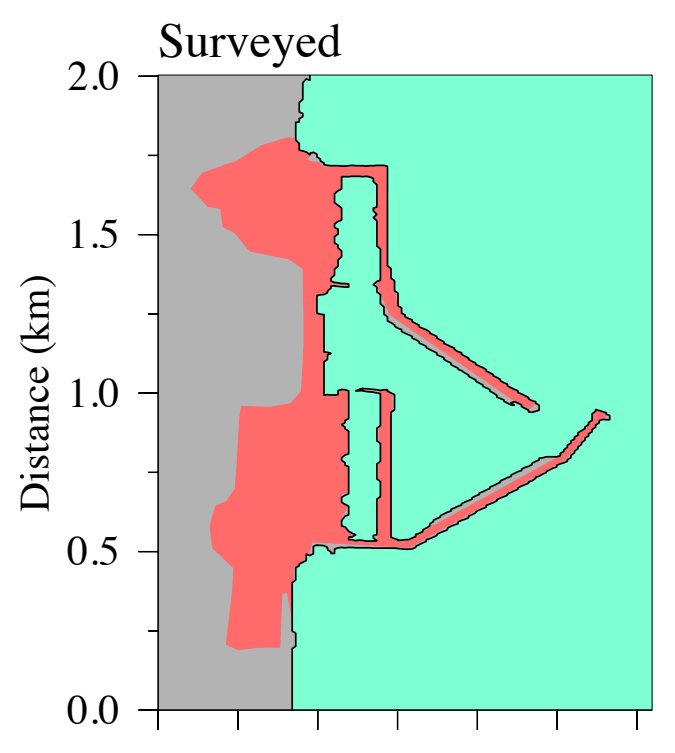

Modeled: case-b
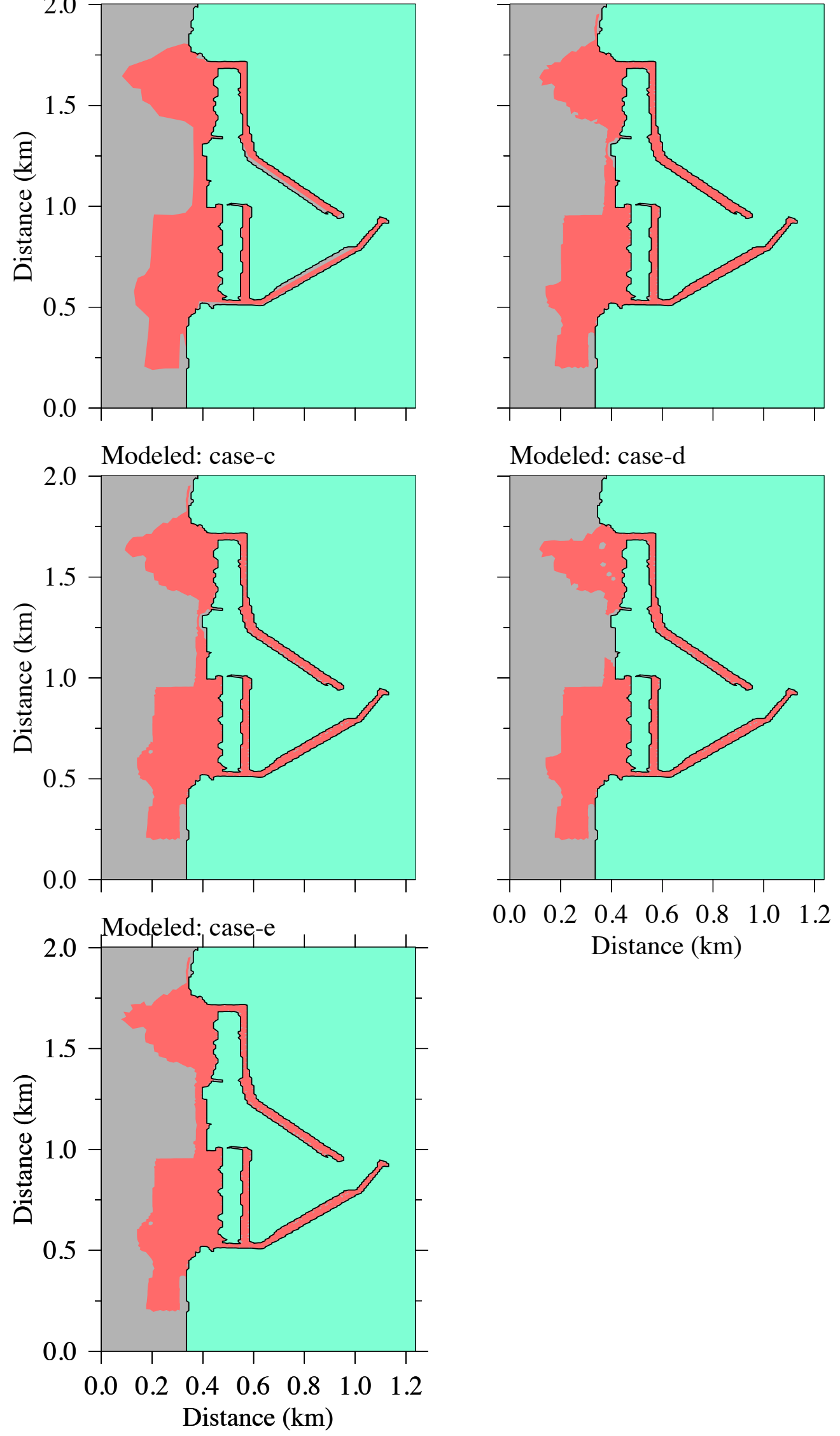

Fig.B5 